\title{
Lecturas territoriales: nuevas cartografías interpretativas de la Quebrada de Humahuaca
}

\author{
Lorena Vecslir \\ Constanza Inés Tommei \\ Clara Elisa Mancini \\ Irenen Nocet ${ }^{*}$
}

1. Una línea de trabajo ampliamente desarrollada en las décadas de 1960 y 1970

por las escuelas morfologistas francesa e italiana para el estudio de la ciudad compacta y que el Laboratorio de Urbanismo de Barcelona retoma a inicios de la década 1980 desde una escala territorial (Solà-Morales, 1981). Posteriormente la investigación sobre la transformación del hábitat urbano en Europa (Secchi, 1993-94) o el estudio ITATEN sobre las formas del territorio italiano (Clementi, Dematteis y Palermo, 1996), entre otros, utilizan metodologías analíticas similares

2. La Quebrada de Humahuaca es un valle montañoso de $155 \mathrm{~km}$ de longitud en dirección norte-sur, ubicado en la Provincia de Jujuy en el extremo noroeste de la República Argentina, recientemente declarado Patrimonio de la Humanidad en la categoría de Paisaje Cultural (UNESCO, 2002).

3. Proyecto ANPCyT 200702102 (2010-2012) “Paisajes culturales y desarrollo local. Evaluación de planes, proyectos y transformaciones territoriales en la Quebrada de Humahuaca y en el Camino de las Estancias", coordinado por Alicia Novick, que reúne equipos de investigación de

las universidades de Tucumán, Córdoba, Rosario, General Sarmiento y Buenos Aires.
La interpretación de las transformaciones físicas del territorio

El análisis del territorio contemporáneo y sus transformaciones más recientes viene siendo abordado desde muy diversos ángulos y disciplinas. La historia, la arqueología, la arquitectura, la antropología y la geografía han sumado lecturas complementarias en la reconstrucción de sus especificidades, en la búsqueda de patrones comunes y sobre todo, de las causalidades o motores del cambio. Atravesando todas estas miradas, el redibujo y la construcción de nuevas cartografías interpretativas aparece como un instrumento de conocimiento indispensable a la hora de interpretar la dimensión física de los procesos, sus impactos en la forma construida (las arquitecturas) pero también en el paisaje, el dibujo del suelo, las líneas y trazados, las permanencias y las persistencias'1.

\section{Especificidades}

Desde esta perspectiva, el trabajo realizado para el territorio de la Quebrada de Humahuaca $(\mathrm{QH})^{2}$, que se inserta dentro de una investigación mayor ${ }^{3}$, busca abordar el análisis espacial del territorio a través de la elaboración de mapas que iluminan sobre algunos aspectos difícilmente perceptibles desde el resto de aproximaciones existentes. Se cruzan aquí las preocupaciones sobre el planeamiento o la gestión de este territorito desde su declaración patrimonial como Paisaje Cultural, con las contradicciones entre el creciente desarrollo turístico y las necesidades locales, entre la salvaguarda del patrimonio y las cada vez más frecuentes ocupaciones de tierras y luchas sociales en los nuevos barrios o asentamientos. De manera complementaria, los mapas nos aportan una mirada física de las transformaciones; nos permiten entender los patrones o modalidades del cambio y las configuraciones territoriales resultantes y lo que es más importante, nos permiten avanzar en la detección de los valores, los temas y los ámbitos prioritarios de intervención, específicos de este contexto patrimonializado.

En la misma orientación, el para qué sirven los mapas elaborados, el trabajo busca superar la condición de la cartografía como mero instrumento para definir áreas homogéneas, redibujando e interpretando aquello que sucede dentro de las mismas, su estructura y principales elementos de cambio,

* Cómo citar este artículo: Vecslir, L., Tommei, C,I.,Mancini, C,E., Noceti, I. (2013). Lecturas territoriales: nuevas cartografías interpretativas de la Quebrada de Humauaca. En Apuntes 26 (1): 114 - 137. 


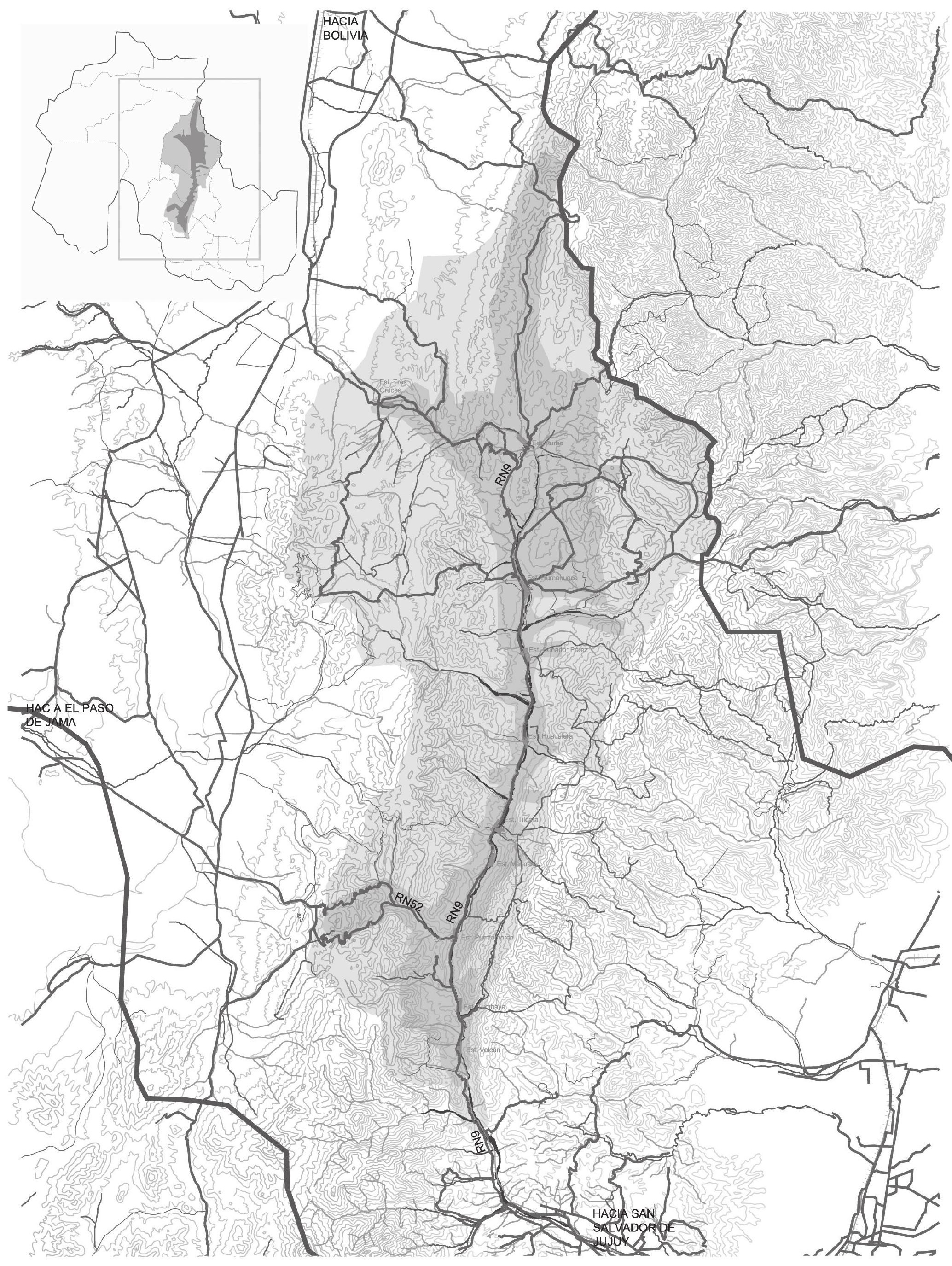




\section{Lecturas territoriales: nuevas cartografías interpretativas de la quebrada de Humahuaca}

Territorial Readings: New Interpretative Cartographies of the Humahuaca Gorge

Leituras territoriais: cartografia nova realização de quebrado humahuaca

\section{Lorena Vecslir}

lorena.vecslir@gmail.com

Arquitecta de la Universidad de Buenos Aires, Argentina. Magíster en Proyectación Urbanística y Doctora por la Universidad Politécnica de Cataluña. Premio extraordinario de doctorado 2004-2005. Investigadora adjunta del Consejo Nacional de Investigaciones Científicas y Técnicas (CONICET) y del Instituto de Geografía (Universidad de Buenos Aires). Miembro del Programa de Investigación sobre Desarrollo Territorial y Estudios Metropolitanos.

Constanza Inés Tommei

ctommei@gmail.com

Arquitecta de la Universidad de Buenos Aires, Argentina. Becaria doctoral del Instituto de Arte Americano e Investigaciones Estéticas "Mario J. Buschiazzo", Facultad de Arquitectura, Diseño y Urbanismo, Universidad de Buenos Aires. Actualmente cursa el Doctorado en Geografía de la Facultad de Filosofía y Letras de la Universidad de Buenos Aires. Su tesis se centra en las transformaciones territoriales en la Quebrada de Humahuaca, con énfasis en el pueblo de Purmamarca, Jujuy.

Clara Elisa Mancini

claraemancini@gmail.com

Antropóloga y profesora en ciencias Antropológicas con orientación en Arqueología de la Universidad de Buenos Aires, Argentina. Becaria doctoral del Consejo Nacional de Investigaciones Científicas y Técnicas (CONICET). Ha trabajado en distintos proyectos arqueológicos y antropológicos en temas relacionados con la Quebrada de Humahuaca desde 2005. Ha participado en actividades de extensión y transferencia y colaborado en distintas cátedras universitarias.

Irene Noceti

irenenoceti@gmail.com

Arquitecta de la Universidad Nacional de Córdoba, Argentina. Cursa el Doctorado en Arquitectura de la Facultad de Arquitectura, Diseño y Urbanismo de la Universidad de Buenos Aires. Su tesis estudia las transformaciones territoriales recientes en la Quebrada de Humahuaca, en particular en el pueblo de Tilcara, Jujuy.

Resumen

El trabajo ensaya el redibujo y construcción de nuevas cartografías de la Quebrada de Humahuaca (Jujuy, Argentina) como un instrumento de conocimiento del territorio a fin de interpretar los procesos de transformación de este Paisaje Cultural antes y después de la Declaratoria UNESCO (2003). La lectura intencionada del territorio, desde diferentes escalas de observación y layers (capas) de información, nos permite indagar en torno a los elementos estructurantes y los patrones del cambio: la asimetría en la forma del relieve y de los cursos de agua, la transversalidad de los ejes de comunicación, la transformación de los tejidos existentes y el crecimiento urbano reciente en pueblos y loteos, así como la evolución en la valoración de los recursos patrimoniales y sitios turísticos. Por último, se abre la discusión en torno a algunos ámbitos y temas renovados de propuesta que surgen a partir del análisis cartográfico y que plantean interrogantes sobre los límites del territorio; el entendimiento de la quebrada como itinerario cultural y la valoración de ciertos subsistemas transversales; así como sobre los patrones recientes del crecimiento discontinuo en nuevos barrios o loteos.

Palabras clave: Paisaje Cultural, proyecto territorial, Patrimonio de la Humanidad, Quebrada de Humahuaca, Jujuy, transformaciones territoriales

Descriptores: Patrimonio cultural-Argentina, turismo cultural, ordenamiento territorial, desarrollo regional, aspectos sociales

Abstract

In order to understand the transformation processes of the Cultural Landscape Humahuaca Gorge (Jujuy, Argentina) before and after the UNESCO declaration (2003), this work essays the redraw and construction of new cartographies as an instrument of territory knowledge. Deliberate reading of the territory, from different scales of observation and layers of information, allows us to delve into the structuring elements and patterns of change: asymmetry in topography and water courses configuration, transversality of communication axes, transformation of existing urban fabric and recent urban growth of towns and allotments, as well as evolution in the assessment of heritage resources and tourist sites. Finally, the discussion focus on some areas and renewed proposal topics arising from the cartographic analysis, and that pose questions about territory limits; the understanding of the gorge as a cultural route and the enhancement of certain cross subsystems; as well as the recent patterns of discontinuous growth in new neighborhoods or allotments.

Keywords: Cultural Landscape, territorial project, World Heritage, Humahuaca Gorge, Jujuy, territorial transformations

Keywords plus: Cultural heritage-Argentina, cultural tourism, land use planning, regional development, social aspects

territoriales en la Quebrada

de planes, proyectos
y transformaciones

de Humahuaca y en el

Camino de las Estancias"

financiado por la Agencia

Nacional de Promoción

Científica y Tecnológica

y coordinado por Alicia

Novick, que reúne equipos

de investigación de las

universidades de Tucumán

Córdoba, Rosario, Genera

Sarmiento y Buenos Aires.

Recepción: 22 de octubre de 2012.

Aceptación: 25 de mayo de 2013.

\section{Resumo}

0 trabalho ensaia o redesenhar e construção de novas cartografias da Quebrada de Humahuaca (Jujuy, Argentina) como um instrumento de conhecimento do território, a fim de interpretar os processos de transformação do presente Paisagem Cultural antes e depois da declaração da UNESCO (2003). Leitura deliberada do território, de diferentes escalas de observação e layers de informação, nos permite mergulhar em torno de estruturação de elementos e padrões de mudanca: a assimetria no caminho o alívio e os cursos de água, a transversalidade de eixos de comunicação, a transformação dos tecidos existentes e o crescimento urbano recentemente em cidades e subdivisões assim como os desenvolvimentos na avaliação dos recursos patrimoniais e locais turísticos. Finalmente, a discussão em torno de algumas áreas e temas renovados decorrentes da análise cartográfica abre e perguntas sobre os "limites" do território; a compreensão do quebrada como uma "itinerário cultural" e o reforço de determinados subsistemas cruzados; bem como os padrões recentes do crescimento descontínuos em novos bairros ou subdivisões.

Palavras-chave: Paisagem cultural, projeto territorial, Património Mundial da UNESCO, Quebrada de Humahuaca, Jujuy, transformações territoriais

Palavras-chave descritores: Património cultural-Argentina, o turismo cultural, o ordenamento do território, desenvolvimento regional, aspectos sociais

doi:10.11144/Javeriana.APC26-1.Itnc

* Los descriptores y keywords plus están normalizados por la Biblioteca General de la Pontificia Universidad Javeriana. 
ponderando los lugares comunes acerca de los Paisajes Culturales y reflexionando sobre sus límites. Así, el “análisis propositivo” (Sabaté, 2009; Sabaté, 2010) de la QH permite ver y hacer ver, por ejemplo, comunicaciones transversales que se fueron diluyendo a través del tiempo, recursos o pueblos que no aparecen en los mapas turísticos, accidentes geográficos que no remiten a la imagen longitudinal tradicional de este territorio.

\section{Layers (capas)}

Los criterios de selección de las capas temáticas o layers tienen que ver con la intencionalidad de la lectura cartográfica y el rol activo que se adjudica al soporte territorial. De allí que el relieve, la hidrografía, el parcelario o el sistema capilar de caminos se configuren como los elementos estructurantes de los mapas y esquemas elaborados.

A diferencia de la superposición de la información urbana sobre un territorio pretendidamente neutro, entendido como simple telón de fondo, el análisis de los pueblos y asentamientos seleccionados busca ligar o articular la representación del amanzanamiento y el parcelario urbano, con el sistema viario y de caminos a escala territorial, los principales accidentes geográficos (quebradas, abras, cerros), las formas del rururbano y la agricultura periférica.

La combinación selectiva e intencionada de layers y su interpretación se convierten en una fuente primaria, clave en la investigación, dado que proveen datos difíciles de dilucidar solo a partir de las fotografías aéreas, las imágenes satelitales o los relevamientos topográficos de la cartografía militar. Los planos dibujados, por sus escalas y temas, pretenden, de esta manera, construir una imagen inédita de la estructura territorial de la $\mathrm{QH}$ o de algunos de sus pueblos y sus entornos inmediatos, complementaria a la información geo-referenciada a partir de sistemas de información geográfica (SIG), la identificación de hábitats naturales, los mapas históricos o las zonificaciones según usos del suelo.

\section{Multi-escalaridad}

Las tres escalas o dimensiones del análisis (a nivel de toda la quebrada, de los pueblos y de sus áreas de influencia) resulta una forma de aproximación a los mismos procesos (nuevos asentamientos residenciales, turistificación del comercio y de los recursos patrimoniales, transformaciones tipológicas, etc.) desde diferentes perspectivas.

La voluntad de representar estos territorios antes y después de la Declaratoria se enfrenta asimismo a la dificultad en el manejo de las fuentes, con un salto temporal de setenta años entre el Mapa del Instituto Geográfico Militar (IGM 1936, escala 1:50.000) y las imágenes satelitales de Google Earth (2003, 2010, sin escala) o la cartografía digital elaborada por el Instituto Geográfico Nacional en SIG (IGN 2004, escala 1:250.000). Los cortes temporales intermedios (1960, 2000) solo son posibles a escala de los pueblos donde mejor se representan las huellas del "palimpsesto" territorial (Corboz, 1983) y las características o elementos identitarios de su configuración actual.

Siguiendo las líneas de trabajo y los objetivos enunciados, el artículo se estructura en tres apartados. El primero hace referencia a la $\mathrm{QH}$ como unidad de análisis, interpretando de manera conjunta, para todo el ámbito geográfico del valle, las características del relieve y los cursos de agua; las transformaciones del ferrocarril, el sistema viario y de caminos; el crecimiento urbano reciente en los pueblos y grandes loteos; los bienes declarados y los sitios turísticos. En una segunda sección, la apertura de ventanas territoriales en los pueblos con mayor afluencia turística (Purmamarca, Humahuaca y Tilcara) se utiliza para redescubrir e interrogarse sobre cómo están hechos y cómo pueden transformarse estos lugares; observar sus características geográficas y paisajísticas; los elementos de estructura urbana; el grado de transformación de los tejidos construidos y los nuevos patrones de crecimiento.

Finalmente se reflexiona sobre algunos ámbitos y temas renovados de propuesta surgidos a partir del análisis propositivo que abren la discusión sobre los límites del territorio, la puesta en valor de ciertos subsistemas transversales, el entendimiento de la Quebrada como itinerario culturaly el rosario de pueblos en transformación.

\section{La Quebrada de Humahuaca como unidad de análisis}

La opción de circunscribirse al ámbito de la Declaratoria UNESCO ${ }^{4}$ (extendiendo algunos elementos -curvas de nivel, cursos de agua, vías y caminosmas allá de sus límites) de entrada, no trata de tomar partido sobre la pertinencia de este ámbito sino, por el contrario, busca explorar el contexto
4. La superficie del área protegida es de $172.116,44$ hectáreas y de 365.648,79 hectáreas, si se incluye su zona de amortiguación. 
Figura 1.

El relieve.

Fuente:

Elaboración propia a partir de cartografía digital (1GN, 2004, esc. original. 1:250.000).
5. Cabe aclarar que existen delimitaciones muy variables de la $\mathrm{QH}$, dependiendo de la disciplina de observación. Desde la geografía, la más clásica es aquella que reconoce tres sectores con paisajes y configuraciones topográficas particulares: al sur, desde la desembocadura del Río Grande hasta el volcán del arroyo del Medio; en la sección central hasta el Ilamado angosto de Perchel; y en el extremo norte hasta el poblado de Tres Cruces (Reboratti, García, Albeck, Castro y Arzeno, 2003). Pero aún en esta regionalización se plantean debates en torno a la ubicación de las líneas divisorias entre los tres tramos (Arzeno y Castro, 1998).

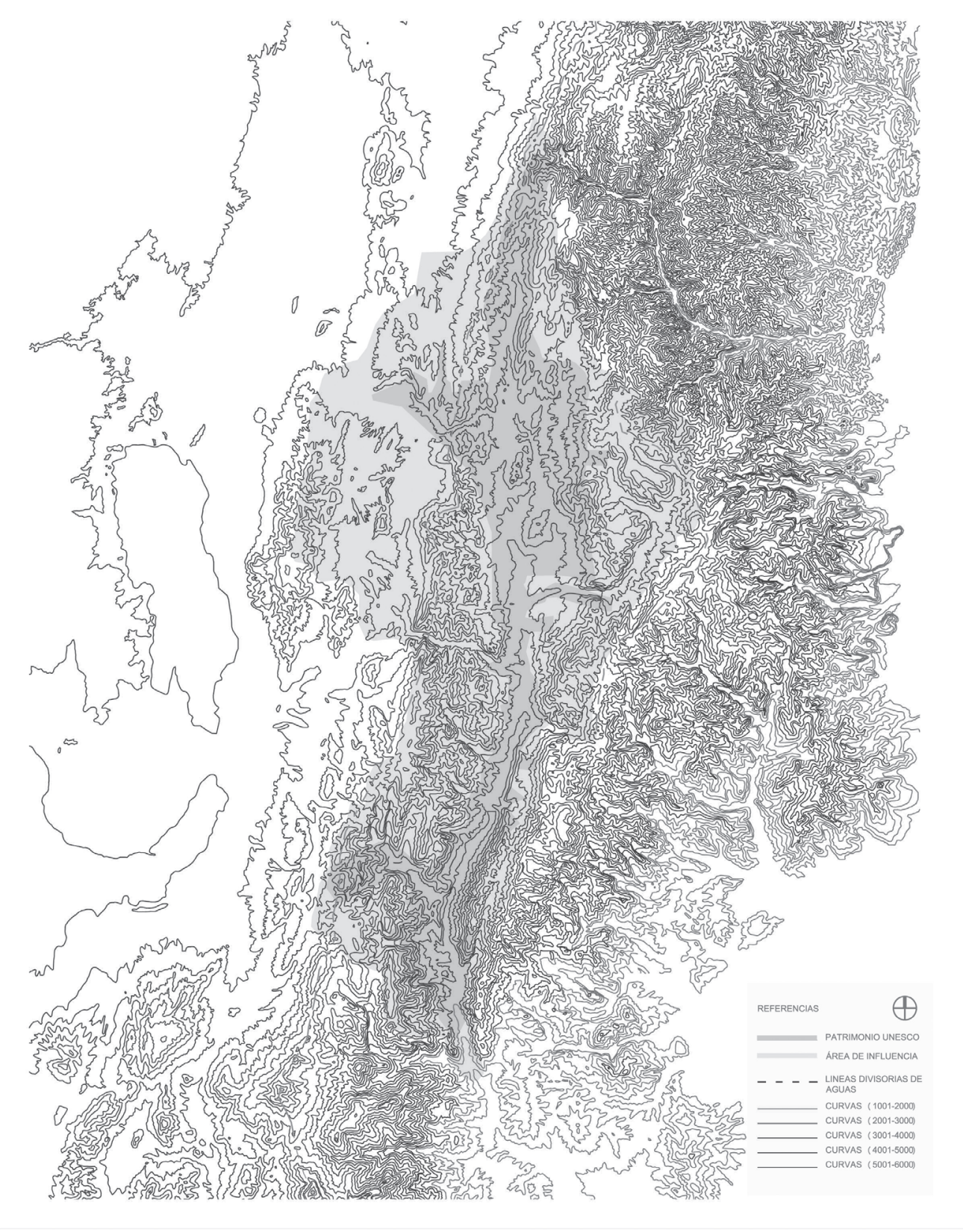

geográfico de la $\mathrm{QH}$ como ámbito geográfico unitario y territorio de paso de clara direccionalidad Norte-Sur (Figuras 1 y 2), a la vez que como lugar de conexiones transversales (Figuras 3 y 4), como rosario de pueblos y nuevos asentamientos (Figuras 5 y 6), como Paisaje Cultural y destino turístico (Figuras 7 y 8 ).

\section{Un valle asimétrico}

El mapa del relieve nos enseña los límites geográficos de la Quebrada, definidos por el fondo de valle del Río Grande, desde su nacimiento al norte en proximidad a la localidad de lturbe (a 3.340m de altitud), hasta su desembocadura al sur en el valle de Jujuy (a una altitud de $1.350 \mathrm{~m})^{5}$. A lo largo de su recorrido se configura un complejo sistema de quebradas menores o valles fluviales transversales de distintos tamaños. En términos generales, hasta la localidad de Humahuaca, la $\mathrm{QH}$ presenta un ancho muy diverso que puede variar entre más de tres kilómetros y menos de 100 metros, en los llamados angostos. A partir de allí, los cordones montañosos se alejan del río que pasa a enmarcarse en un valle no demasiado profundo (Reboratti et al., 2003).

Una sección amplia de la $\mathrm{QH}$ nos muestra la asimetría de sus bordes. Al oeste, luego de un 
alto cordón montañoso de orientación Norte-Sur, aparece el territorio de la Puna con cotas constantes relativamente altas. Se eligió la cota 3.600 (msnm) para dar fin al mapa y evidenciar el sector del Altiplano y su homogeneidad de alturas. También se dibujó la línea divisoria de aguas entre la Puna y la Cuenca del Río Grande, que constituye el verdadero límite físico o telón de fondo de la Quebrada, configurado por la Sierra de Aguilar (5.000 m), la Sierra del Alto y la Sierra de Chañi, que culmina con el nevado de Chañi (6.200 m). El límite Este en cambio, resulta menos definido, observándose una transición más gradual hacia las Sierras Subandinas (región Yungas) y de estas a la llanura chaqueña. La línea divisoria de aguas, menos continua y elevada en este caso, está representada por las sierras de Santa Victoria, Zenta y Tilcara y el sector septentrional de las Sierras de Zapla.

Resulta interesante observar desde la topografía las relaciones transversales al valle del Río Grande, que históricamente han permitido el paso hacia las áreas adyacentes. Se trata de las quebradas laterales, algunas de las cuales, desde el oeste, han servido como caminos principales (Purmamarca yacoraite y las nacientes en el sector de Tres Cruces) mientras que otras (Huichaira, Juella y Coraya) tienen un carácter secundario. En la margen izquieda del Río Grande destaca la Quebrada de Calete vinculada con el Abra de Zenta $^{6}$. Asimismo, vale la pena mencionar como característica distintiva de la $\mathrm{QH}$ y condicionante para el asentamiento humano, los volcanes, nombre que se le da en la zona a la caída o flujos de barro desencadenados a raíz del relieve abrupto, el clima y el arrastre de sedimentos provocado por las intensas precipitaciones estivales sobre suelos poco consolidados (González, Baumann y Jackson, 2009).

\section{La transversalidad del territorio}

La Quebrada, como ya se ha mencionado, posee una direccionalidad natural Norte-Sur. En ambos planos (Figuras 3 y 4) pueden observarse los principales elementos de comunicación que la estructuraron en esa dirección a lo largo de la historia: el ferrocarril General Sarmiento, hoy desactivado y la Ruta Nacional 9, RN9. El ferrocarril recorría, desde principios de siglo XX, la totalidad de la Quebrada, vinculando San Salvador de Jujuy con Bolivia. Alrededor de 1990 quedó desafectado y su

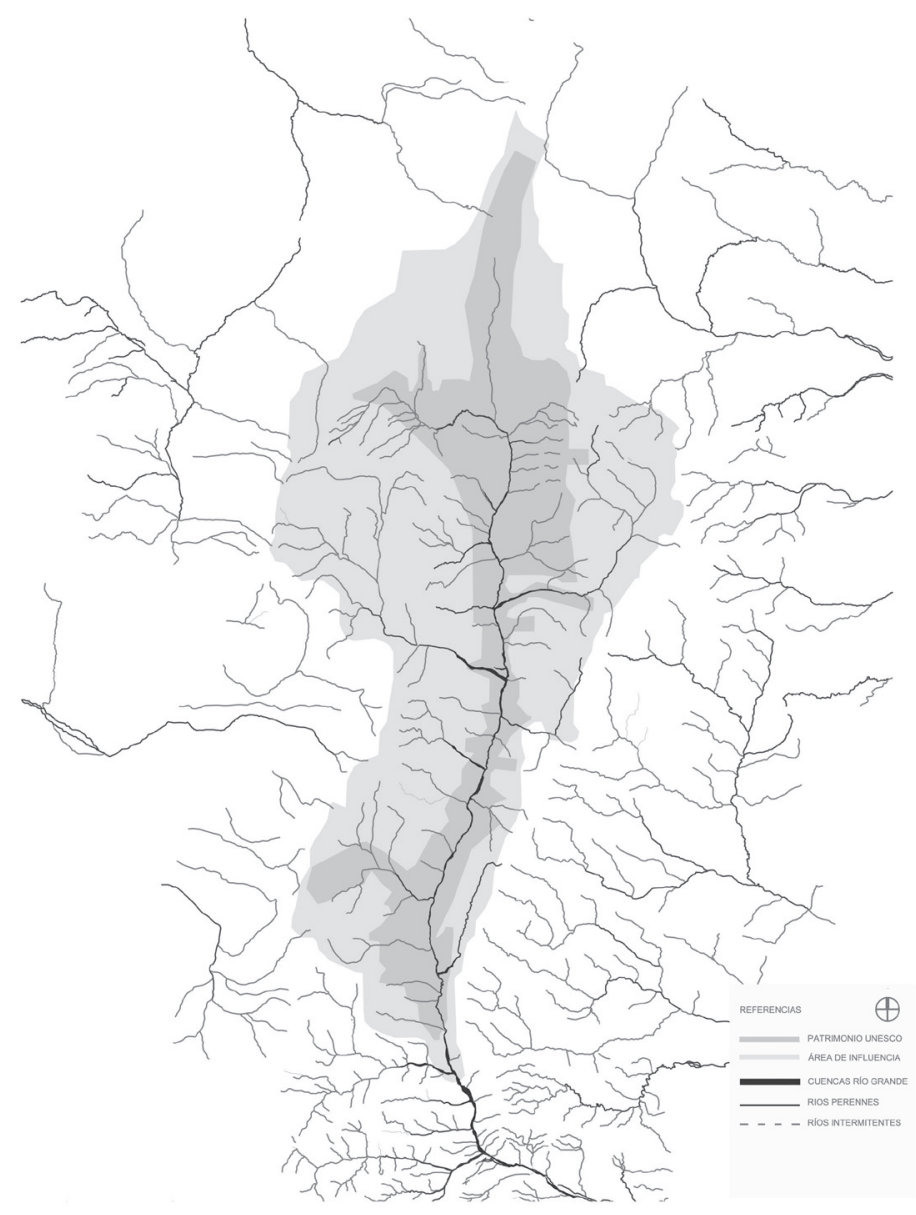

infraestructura fue abandonada. La RN9, si bien se comenzó a construir en 1940, no llegó a tener mayor importancia hasta principios de la década de 1970 cuando fue pavimentada.

En sentido transversal al valle del Río Grande, varias conexiones en diferentes períodos históricos vincularon la QH con la Puna, hacia el oeste y con las Yungas, hacia el este. Desde un primer momento, estos intercambios fueron de gran relevancia gracias a la variación de la producción en las tres regiones (Puna, Quebrada y Yungas). El plano de 1936 nos enseña por ejemplo, la importante conexión que existía entre Humahuaca y Tres Cruces con la mina El Aguilar. En aquel momento ese camino constituía (según la nomenclatura de la Carta Militar) una rodera o huella" la siguiente jerarquía en calidad de transitabilidad luego del camino consolidado de la RN9. Asimismo, con relación al transporte de minerales existía un camino que vinculaba la región puneña con la QH pasando por Purmamarca (Benedetti, 2003). En la actualidad este constituye el principal vínculo en sentido transversal debido al trazado de una ruta de conexión con Chile a
Figura 2.

Los cursos de agua. Fuente:

Elaboración propia a partir de cartografía digital (1GN, 2004, esc. original. 1:250.000).

6. Los pasos serranos, localmente denominados abras o portillos constituyen los espacios utilizados para transponer las cadenas montañosas y pasar de una cuenca o sub-cuenca hidrográfica a otra. 
Figura 3. Las comunicaciones (ferrocarril, ruta y caminos), 1936.

Fuente:

Elaboración propia a partir de Carta Militar

(1GM, 1936, esc. original. 1:50.000).
7. De norte a sur: Tres Cruces, Hipólito Yrigoyen, Humahuaca, Tilcara, Maimará, Hornillos, Purmamarca, Tumbaya y Volcán.

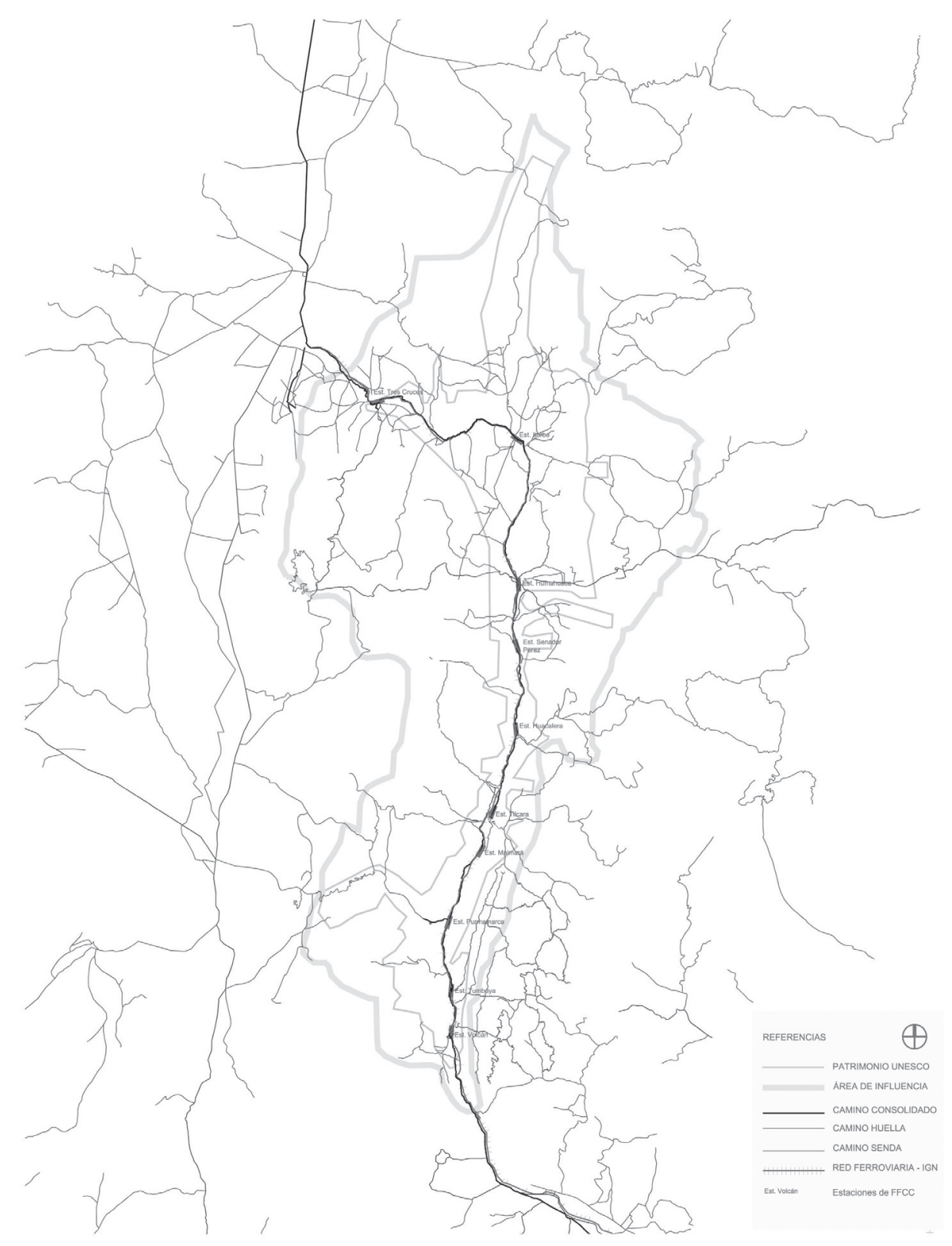

través del Paso de Jama. En 1970 comenzaron las obras pero recién a inicios de la década de 1990 fue asfaltada esta ruta nacional (RN52) y empezó a tener razonables condiciones de accesibilidad (Ballatore, 2005).

La conexión transversal hacia el este también existe desde la década de 1930. El principal vínculo, por su calidad de huella, partía desde el pueblo de Humahuaca para acceder a las Yungas y las tierras bajas del Chaco oriental, a través de la Quebrada de Calete. En la década de 2000, no se ven nuevos caminos en esta dirección, pero sí el mejoramiento general de los mismos, en particular, el del mencionado camino, hoy convertido en la Ruta Provincial 73 (RP73). Un importante cambio en las vías de comunicación, que se visualiza entre los dos momentos analizados, es el incremento y mejora de los vínculos viales existentes hacia el sur de la Quebrada, conectándola con diferentes puntos de la región del valle de Jujuy.

\section{Pueblos y loteos: el crecimiento urbano reciente}

El redibujo de las manchas urbanas, capaces de ser visualizadas en esta escala de trabajo, toma como base a los pueblos que figuran en el relevamiento del IGM realizado en 1936 y los recogidos en el documento de la Declaratoria (UNESCO, 2002) ${ }^{7}$. A partir de su comparación, se pueden observar los 


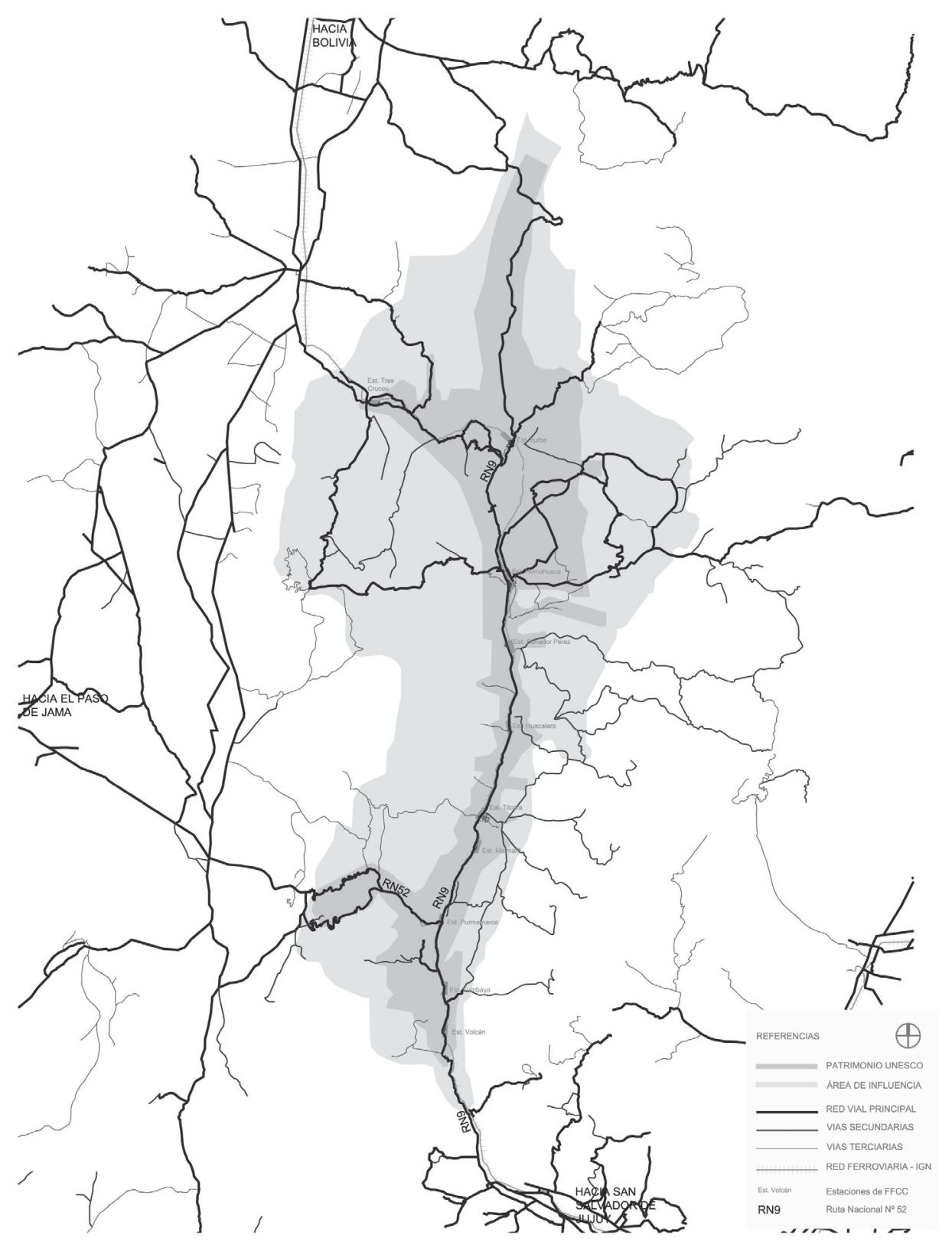

cambios y las permanencias de los núcleos urbanos en el período estudiado. Desde esta perspectiva, algunos asentamientos (Humahuaca, Tilcara, Maimará) se han desarrollado por agregación de nuevas manzanas, extendiendo la mancha urbana. Otros (como Uquía y Volcán) han permanecido casi sin modificación a lo largo del tiempo. También existen cascos históricos a los que se les han sumado nuevos barrios en continuidad con la trama existente, así como nuevos loteos inconexos con la mancha urbana original (por ejemplo, 2 de Abril cerca de Humahuaca; Sumay Pacha, entre Tilcara y Maimará; y Chalala, aproximadamente a dos kilómetros de Purmamarca).
Los motivos o motores de los cambios relativos al crecimiento (o mantenimiento) de los diversos núcleos urbanos oscilan en primer lugar, sobre el gradual crecimiento del turismo a lo largo del siglo XX y el boom turístico en el siglo XXI. Esto resulta especialmente notorio en las localidades de Tilcara, Purmamarca y Humahuaca, donde destaca la construcción de una importante cantidad de infraestructura hotelera o de alojamientos destinados para tal fin (Janoschka, 2003; Troncoso, 2008). En segundo lugar podemos mencionar el cese, disminución o mecanización de varias de las actividades que generaban importantes fuentes de mano de obra
Figura 4.

Las comunicaciones (ferrocarril, ruta y caminos), 2004.

Fuente:

Elaboración propia a partir de cartografía digital (1GN, 2004, esc. original. 1:250.000) e imágenes satélitales de Google Earth. 
Figura 5. Los pueblos, 1936.

Fuente:

Elaboración propia a partir de Carta Militar

(IGM, 1936, esc. original. 1:50.000).

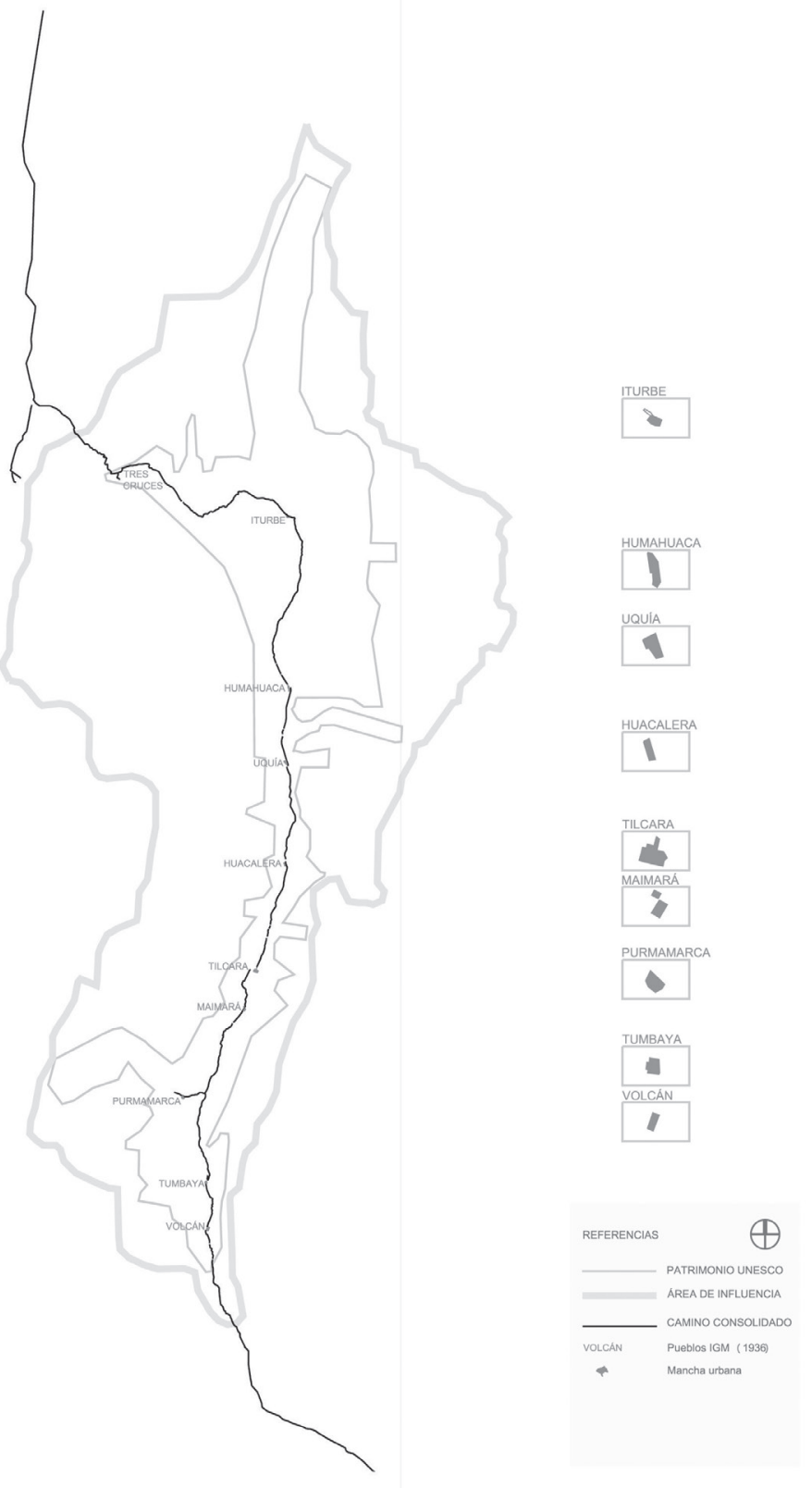

en la zona: la producción de azúcar, tabaco, acero y minerales y el cierre del ferrocarril, que afectó significativamente otras actividades productivas. Esto implicó una migración de muchos pobladores de asentamientos menores o zonas rurales hacia los pueblos de mayor tamaño de la Quebrada, como Maimará, Tilcara o Humahuaca (Benedetti, 2003).

Por último, cabe destacar como motor de la transformación urbana reciente, la construcción de vivienda social por parte del Estado y los asentamientos informales surgidos en los últimos veinte años, que han tenido un fuerte impacto en Maimará, Tilcara, Humahuaca y Purmamarca (Rotondaro, 2001). Esta tendencia se ha acentuado en la última década, contabilizándose entre los años 2003 y 2011, 761 nuevas viviendas pertenecientes a diversos planes sociales con financiamiento del gobierno nacional, la mayoría de ellos construidos en Humahuaca (Potocko, 2011a).

En síntesis, la cartografía elaborada nos permite diferenciar los principales enclaves turísticos del periodo 1936-2004 (Purmamarca, Tilcara, Maimará y Humahuaca); los crecimientos por migraciones internas (en Humahuaca y Maimará); los pueblos estancados desde el punto de vista de su crecimiento urbano (Uquía y Volcán), así como los grandes loteos llevados a cabo en las últimas dos décadas (2 de Abril, Sumay Pacha y Chalala). 

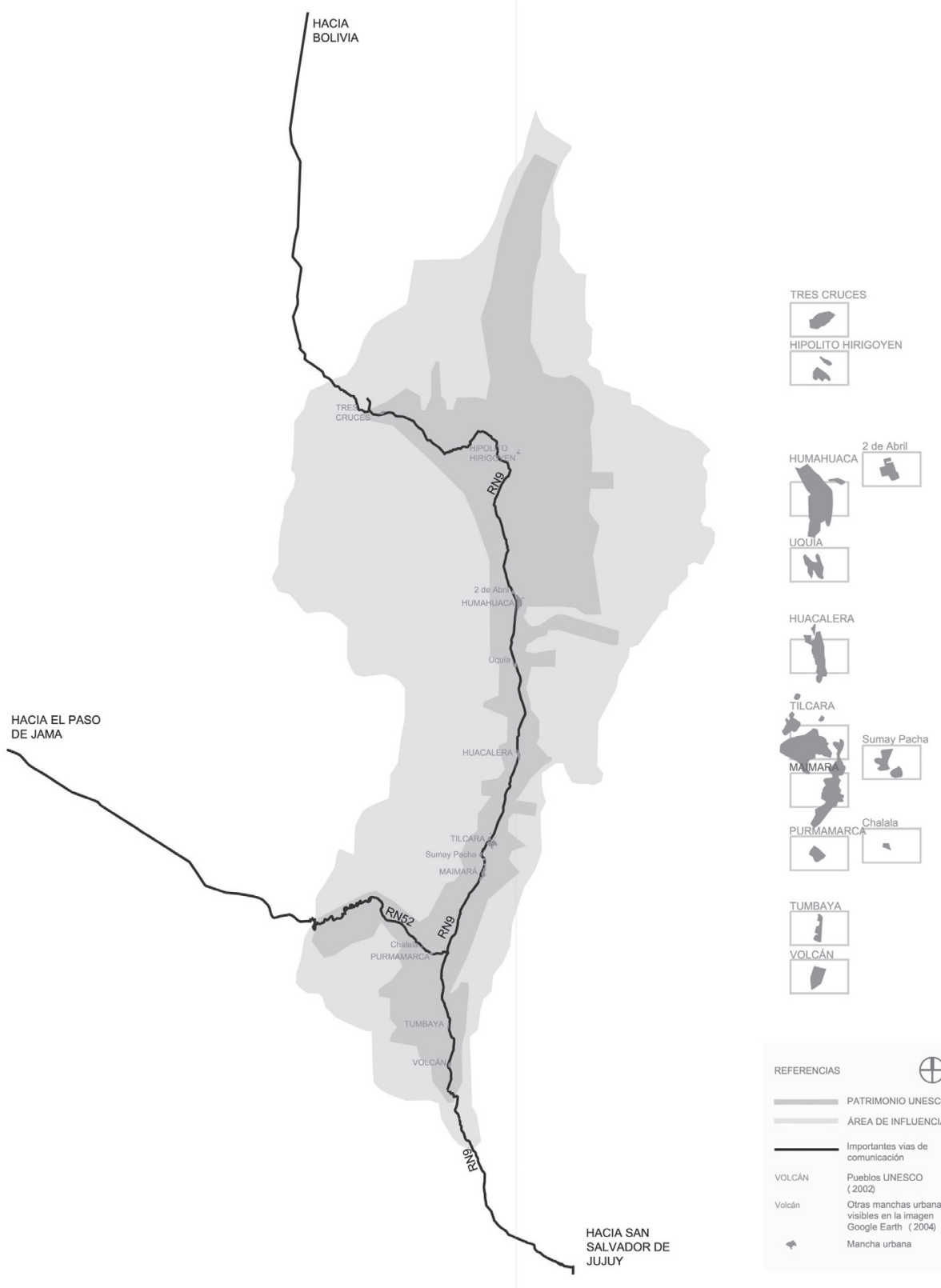

Bienes declarados y sitios turísticos: la diferente valoración de los recursos

Los distintos bienes patrimoniales de la Quebrada han recibido un tratamiento muy diverso a los largo de todo el siglo XX (Mancini, 2011; Mancini y Tommei, 2012). Por un lado, desde las declaraciones o las normativas y por otro, desde el saber experto se fueron seleccionando y valorando ciertos bienes sobre otros. Diferentes profesionales del campo de producción de bienes culturales patrimoniales han valorado objetos, sitios y el paisaje y a su vez, solo algunos de ellos han sido protegidos por leyes de diferentes escalas.
En términos generales podemos vislumbrar tres momentos propuestos de institucionalización del patrimonio en la Quebrada, que se distinguen más claramente en las normativas que en los estudios académicos. El primer momento, a partir de la década de 1930 , se caracteriza por la valoración de las capillas. El segundo momento, a partir de mediados de siglo XX, aparece con normativas e investigaciones que reconocen algunas pocas construcciones privadas y dos pueblos, dejando así muchos casos sin ser valorados, a pesar de tener similares características. El último momento, que comienza entre las décadas de 1980 y 1990, está marcado por las acciones
Figura 6.

Los pueblos y grandes loteos, 2004.

Fuente:

Elaboración propia a partir de cartografía digital (1GN, 2004, esc. original. 1:250.000) e imágenes satélitales de Google Earth. 


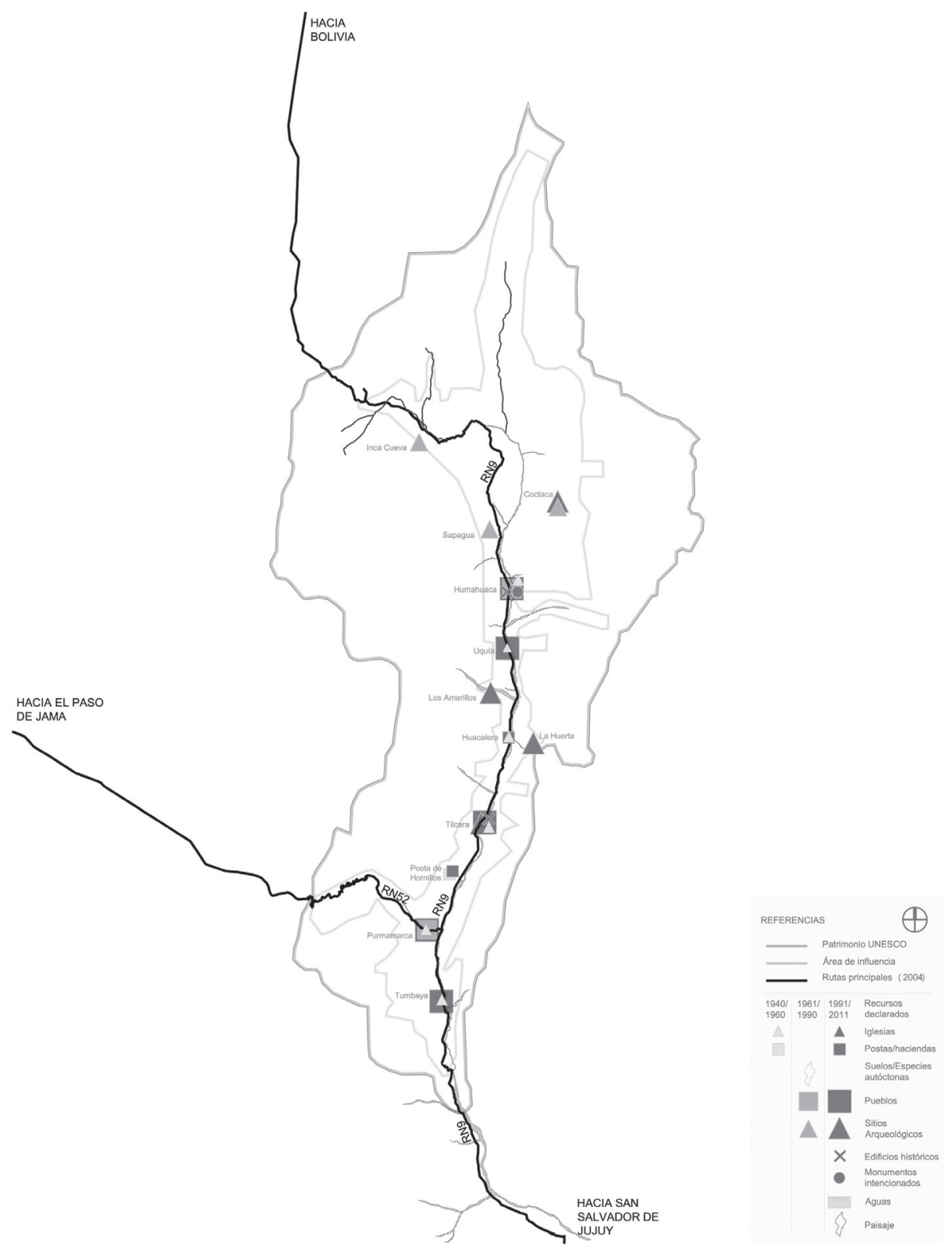

tendientes a la postulación ante la UNESCO. Con este objetivo se realizan varios estudios y leyes que abarcan todo el territorio de la Quebrada y conjuntamente se amplía la lista de bienes, especialmente de sitios arqueológicos y elementos arquitectónicos hasta ese momento no reconocidos (Mancini, 2011; Mancini y Tommei, 2012). Así todos los objetos y sitios de la Quebrada que habían tenido una trayectoria desigual se subsumen ahora en una única categoría, la de Paisaje Cultural. Podría decirse que esta homogeneización es uno de esos resultados contradictorios de las catalogaciones de corte universalista, en la medida en que disuelven lo particular en lo universal.
Hasta la época de la Declaratoria el acervo patrimonial de la Quebrada era reconocido y mencionado pero no era explotado desde el turismo. Se daba el turismo hacia la región (a veces por el clima, a veces por el paisaje de montaña, a veces por la fama del carnaval, a veces por la arquitectura colonial) pero no se explotaba la patrimonialización como recurso turístico. En cambio, a partir del 2003 se resaltan las legislaciones patrimoniales y las guías incorporan como parte de la descripción de la Quebrada, la declaratoria UNESCO.

En este sentido resulta interesante reflexionar sobre la participación activa del turismo en la selección y valorización del patrimonio 


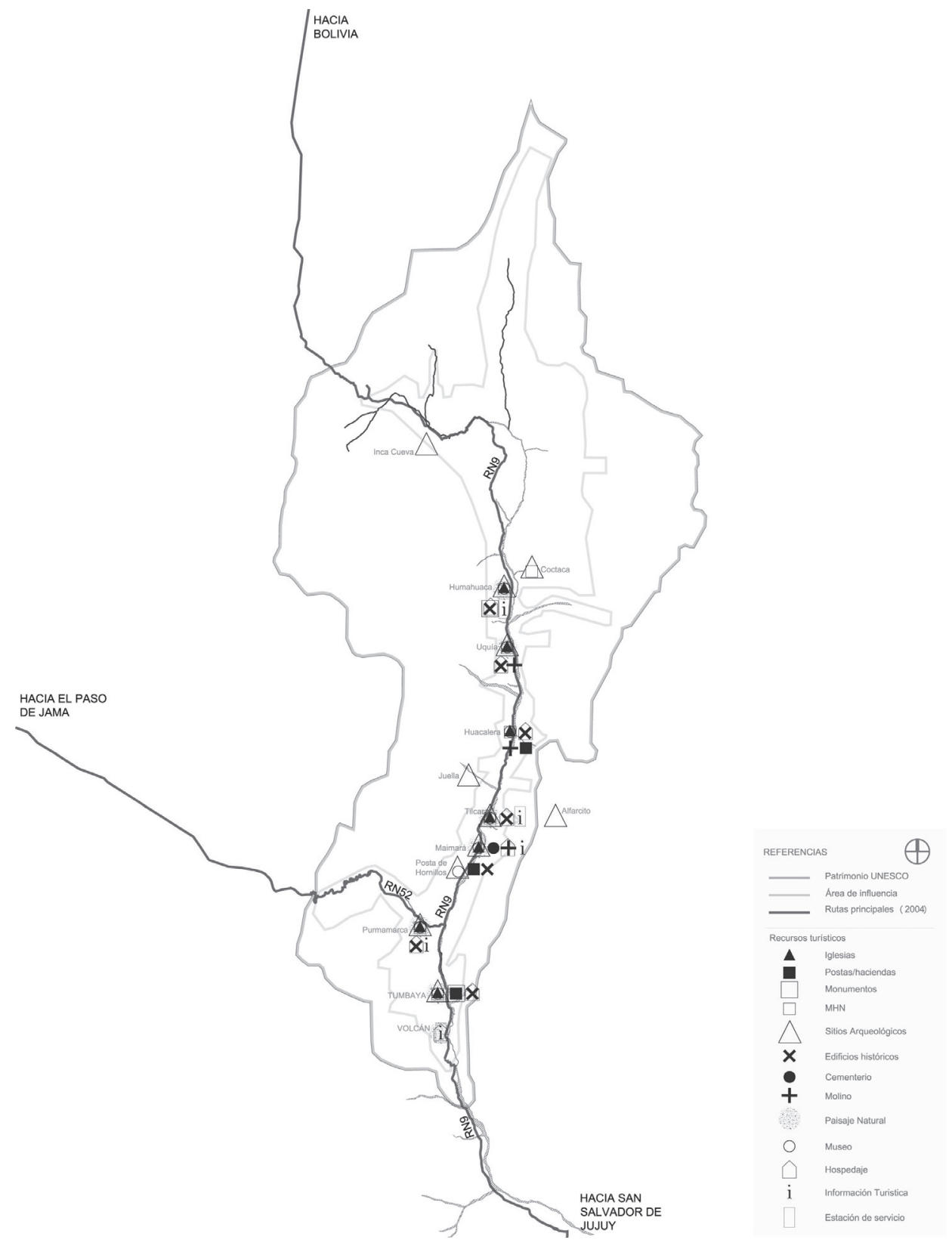

(Troncoso y Almirón, 2005). Por ejemplo, en el rol que se le asigna a Tilcara como "capital arqueológica” (reconocida por decreto en 1967), ligado a su habilitación como lugar turístico desde su descubrimiento y restauración, en especial al proyecto llevado adelante por Casanova, que incluyó el camino de acceso de autos y museo (Mancini, 2011). Asimismo la selección de los pueblos que se mencionan en la postulación de la $\mathrm{QH}$ ante la UNESCO no se distingue demasiado del mapa de recursos turísticos. El turismo ha formado ciertas imágenes mentales sobre los pueblos de la quebrada que afectan la forma en que ese patrimonio se ofrece y se protege. Por ejemplo, la asociación de Purmamarca al Cerro de los Siete Colores, que prácticamente se ha convertido, en las últimas décadas, en la imagen distintiva de todo el territorio de la $\mathrm{QH}$ (Tommei y Benedetti, 2011). Puede decirse algo similar del cerro la Paleta del Pintor del pueblo de Maimará.

La oferta de la quebrada como Paisaje Cultural, Patrimonio de la Humanidad, intenta mostrar un paisaje impactante por su belleza y por ser testimonio del pasado en el presente (bajo la consigna de "10.000 años de hombre y su ambiente”). La idea de tiempo detenido es algo que busca brindarse para el consumo, a la vez que el propio turismo ha sido un agente activo en las transformaciones territoriales de la $\mathrm{QH}$ a
Figura 8.

Los recursos turísticos.

Fuente:

Elaboración propia a partir de diversas guías turísticas. 
8. El trabajo se realizó en base a las siguientes fuentes cartográficas: planos de Purmamarca elaborados por Alberto Nicolini en 1964, plano de Humahuaca del Catastro Provincial de 1967, imagen satelital de Tilcara del IGM de 1975, imágenes satelitales del Google Earth (Humahuaca, 2004; Tilcara, 2010 y Purmamarca,

2007) y planos catastrales de la Provincia de Jujuy, facilitados por la Unidad de Gestión en el 2008.
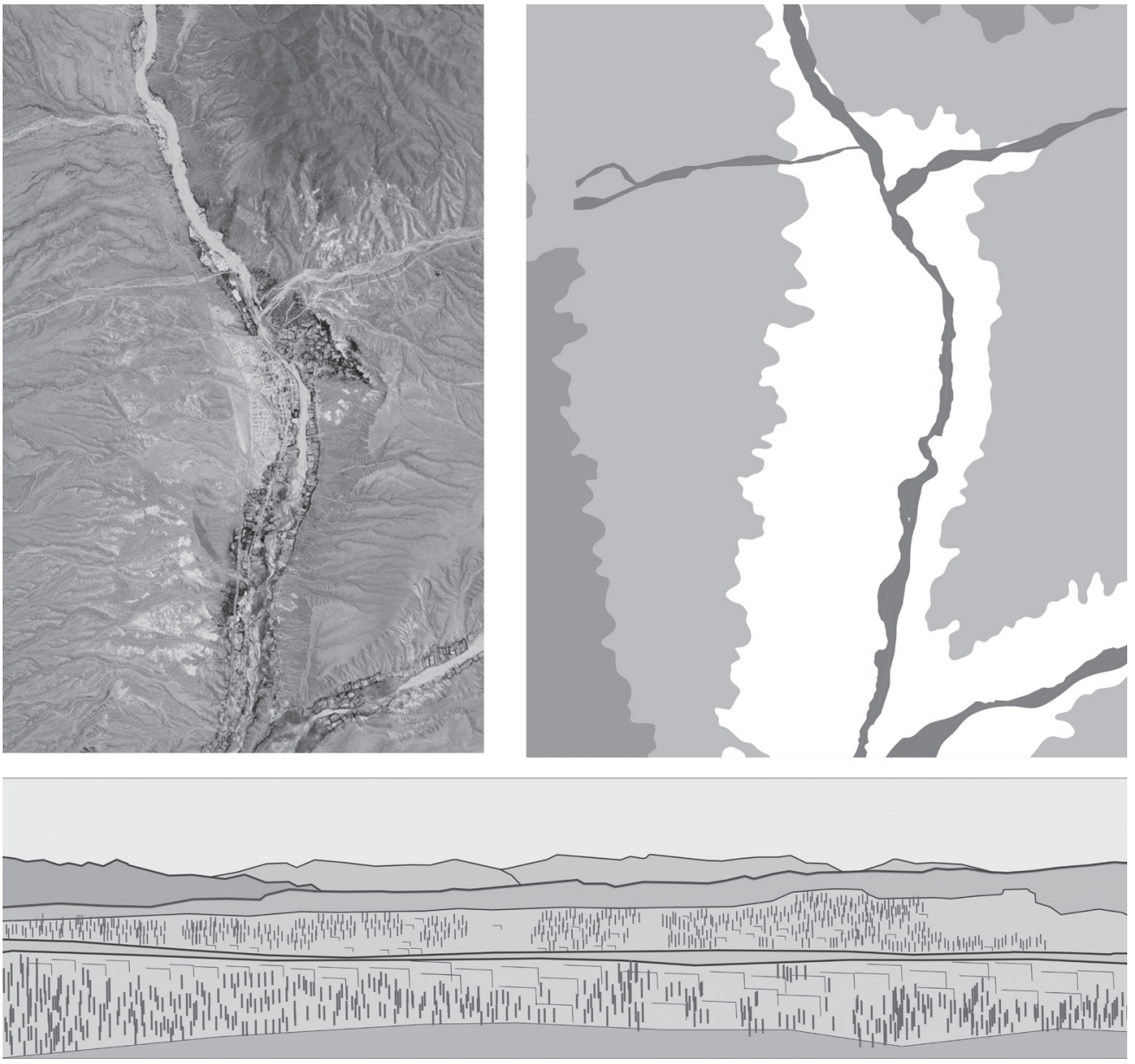

lo largo de todo el siglo XX. En este sentido, una de las grandes contradicciones entre el saber experto y lo que proponen las guías de turismo puede verse en Humahuaca. Mientras que para los primeros se trata de un lugar muy alterado, de conservación regular (UNESCO, 2002) para las guías alli es "donde conviven pasado y presente".

Es remarcable que los circuitos turísticos se configuren linealmente, a través de las vías del tren primero y de la RN9 después. En general se propone como lugares para la estadía más prolongada a Tilcara y Humahuaca. Los itinerarios se piensan para pasar velozmente por la mayoría de los lugares y regresar a hospedarse en uno de los dos pueblos. Tilcara es elegida como la villa veraniega predilecta. Desde hace poco más de una década Purmamarca e Iruya se agregan como lugares destacados de este circuito (esta última ubicada fuera del ámbito de la Declaratoria). En este sentido, si bien el patrimonio está presente en toda la $\mathrm{QH}$, el turismo ha construido su propio itinerario, que sobre-explota algunos lugares y deja otros con los mismos recursos por fuera.
Ventanas territoriales: Purmamarca, Humahuaca y Tilcara

En una segunda fase del trabajo, a partir del redibujo de algunos pueblos y sus áreas de influencia en escala 1:10.000 y 1:25.000, se buscó una mayor aproximación al análisis interpretativo del territorio y sus transformaciones urbanas ${ }^{8}$. Como muestras representativas de los cambios en curso, se seleccionaron tres casos de estudio coincidentes con las localidades de mayor dinamismo, crecimiento urbano y afluencia turística en los últimos años: Purmamarca, Tilcara y Humahuaca. Para complementar las lecturas planimétricas mediante capas o layers de información, se analizaron imágenes panorámicas, representativas del paisaje de cada uno de los pueblos. Debido a la diversidad de factores y elementos que intervienen en la definición morfológica del paisaje, para una mejor comprensión del objeto de estudio, se redibujaron de manera muy simple, primero los elementos estructurales (cerros, fondo de valle y ríos) y luego, otros elementos característicos (construcciones, vegetación e infraestructura). 


\section{La forma del suelo como condicionante del crecimiento y recurso paisajístico}

La topografía del espacio quebradeño (representada por cotas cada $200 \mathrm{~m}$ ) distingue y a su vez condiciona la forma y el crecimiento urbano de cada uno los pueblos analizados. Humahuaca por ejemplo, se emplaza sobre la ladera del cerro Santa Bárbara (2939 msnm) y a diferencia de los otros dos pueblos, posee una situación topográfica en la que el telón de fondo definido por las montañas se separa, generando un valle amplio y llano. Los cerros del límite Este son los más visibles desde el interior del pueblo y morfológicamente configuran dos capas. La primera, en tonos rojizos con una altura casi constante y en un segundo plano, una cadena montañosa en tonos grisáceos de forma irregular. La pendiente del terreno donde se asienta presenta un salto abrupto Oeste-Este, dejando a la vista dos niveles bien diferenciados: uno superior donde se sitúa la RN9 y uno inferior en el que se emplaza el casco urbano y el Río Grande (Figura 9).

El pueblo de Tilcara constituye una excepción dentro de los pueblos quebradeños en su posición respecto al Río Grande, emplazándose en la orilla izquierda del mismo ${ }^{9}$. Los cordones montañosos que encierran el núcleo, asentado a $2461 \mathrm{msnm}$ sobre una pronunciada pendiente de dirección Norte-Sur, difieren en morfología, colores y tonalidades. La cadena montañosa del lado este del río configura un fondo relativamente continuo y homogéneo que contrasta con el límite Oeste, de morfología más compleja y desigual, configurado por una sucesión de capas superpuestas. Destacan en este sector las quebradas laterales de Huichaira, al sur del pueblo y la de Jueya, al norte del mismo (Figura 10).

El pueblo de Purmamarca se sitúa a 2275 msnm sobre la quebrada homónima, a una distancia de aproximadamente cuatro kilómetros de la RN9 y el Río Grande. El casco urbano se implanta en un estrecho valle encajonado entre pendientes abruptas e importantes barreras físicas: al norte, la RN52, el río Purmamarca y el cerro Morado; al este, el arroyo y Quebrada de Tumbaya; al sudoeste, el Cerro de los Siete Colores y el Cerro Verde, entre otros. La topografía que rodea al poblado es a la vez un problema para la expansión de la aglomeración y un recurso paisajístico (Figura 11).

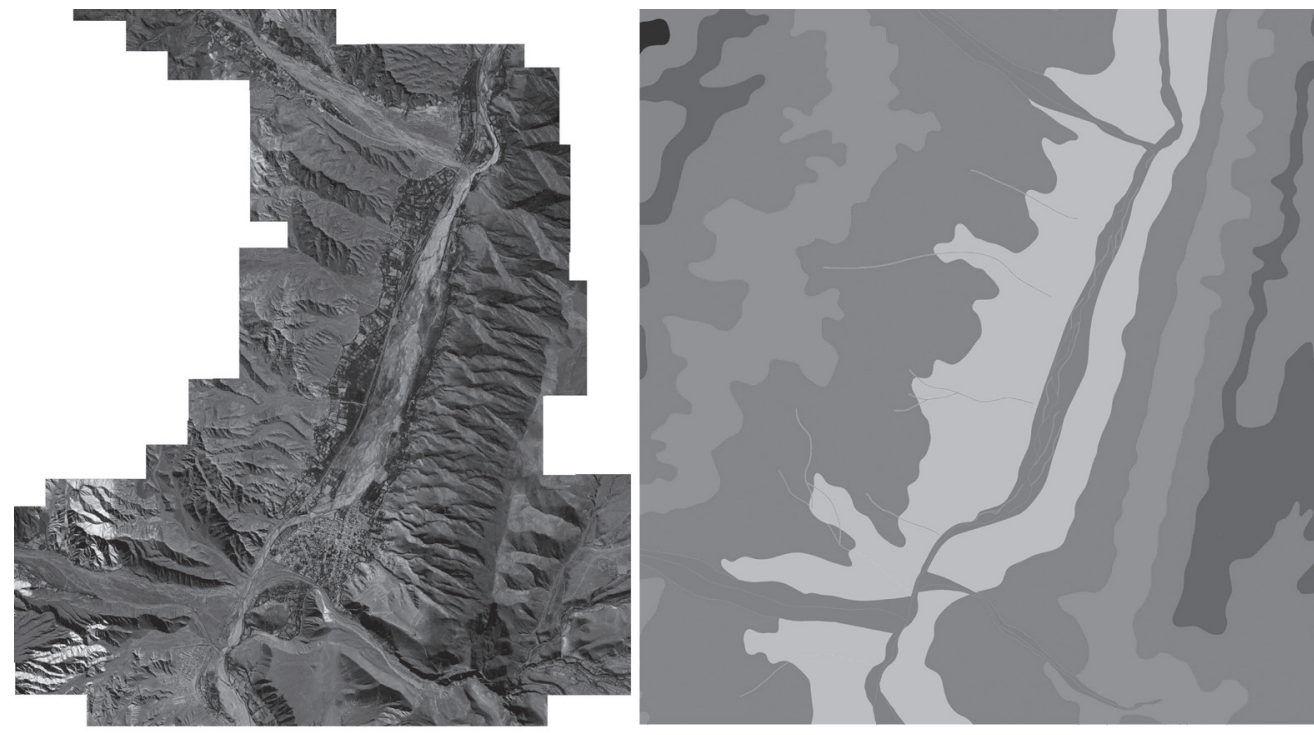

Figura 10.

a) Imagen satelital de Tilcara.

Fuente:

Google Earth, 2004;

b) Red hidrográfica y topografía del emplazamiento.

Fuente:

Elaboración propia; c) Análisis del paisaje sobre una imagen panorámica.

Fuente:

Elaboración propia.

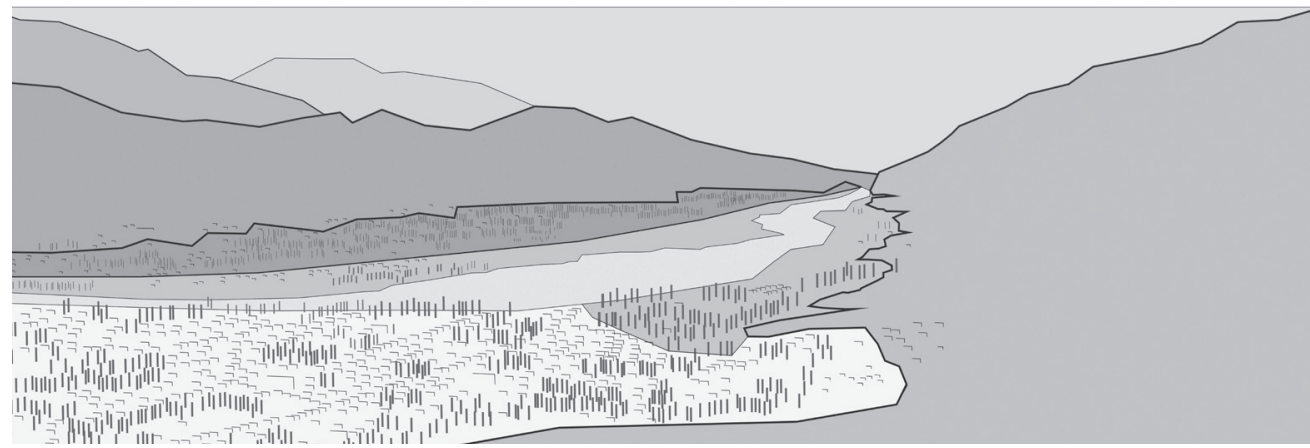

9. Esto se debe a su asentamiento sobre el abanico construido por el material aluvial que arrastró el torrente del Huasamayo, una quebrada lateral al valle del Río Grande. 

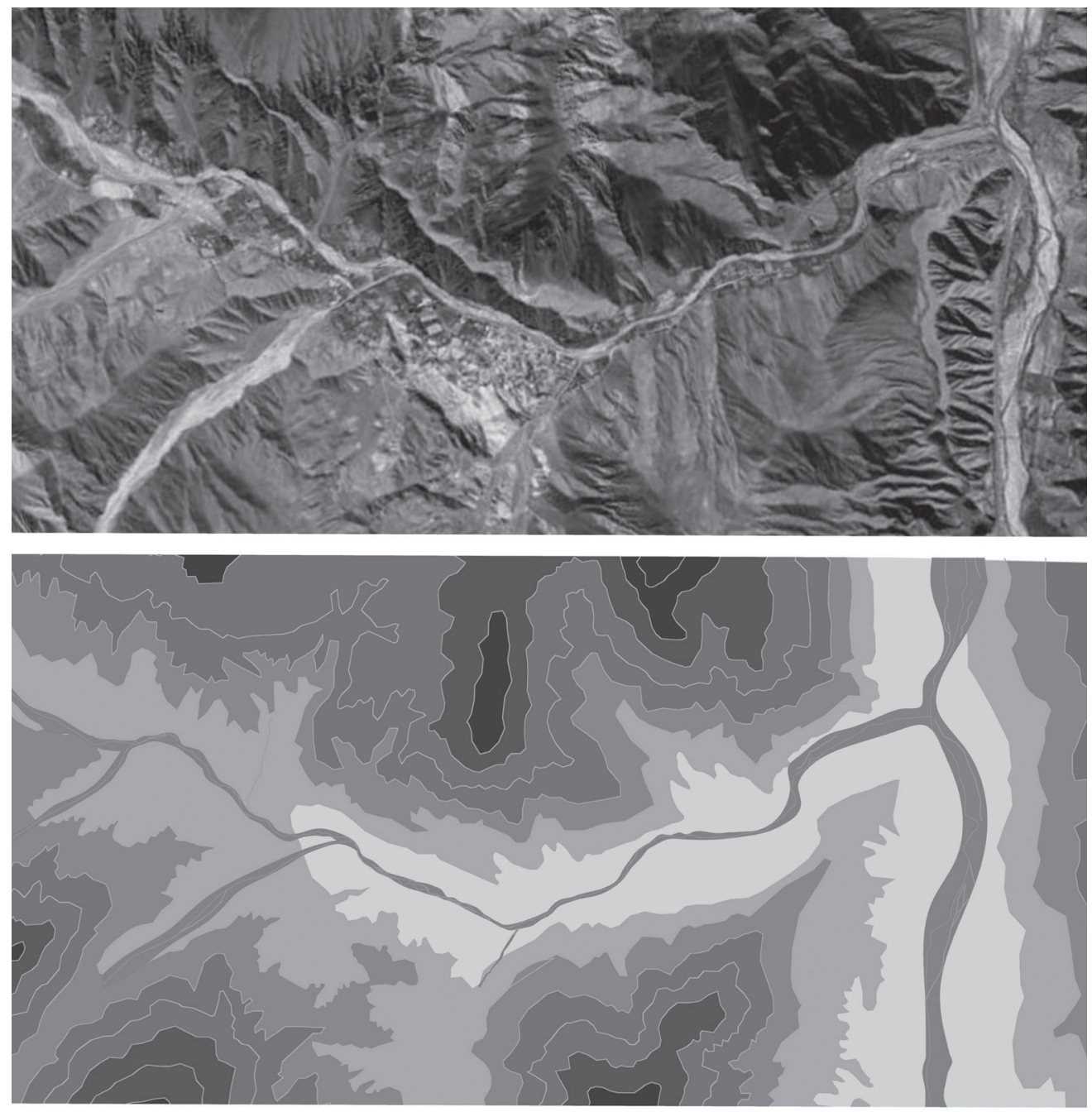

a) Imagen satelita de Purmamarca.

Fuente:

Google Earth, 2004;

b) Red hidrográfica

y topografía del emplazamiento.

Fuente:

Elaboración propia;

c) Análisis del paisaje sobre una imagen panorámica.

Fuente:

Elaboración propia.

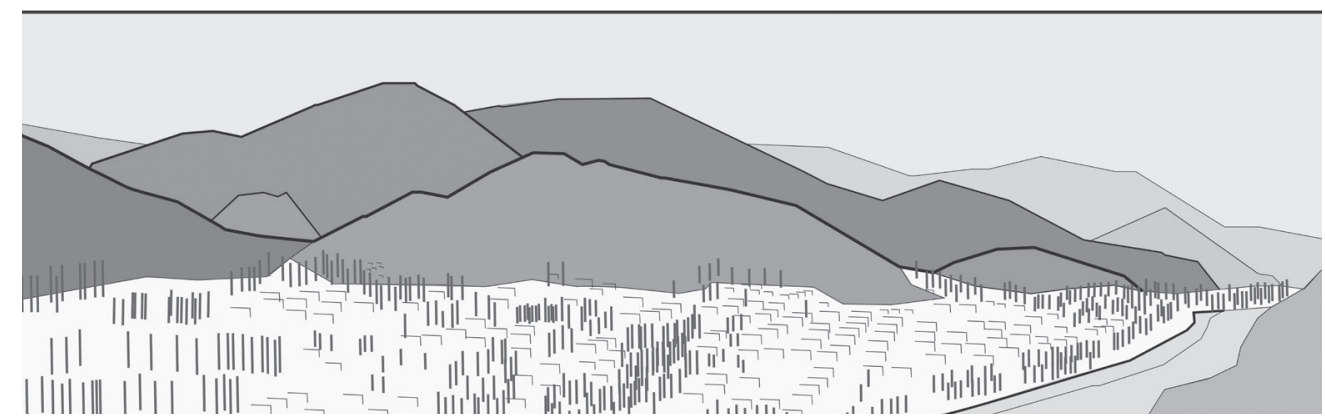

\section{Elementos de comunicación y estructura urbana}

El redibujo de la infraestructura viaria y ferroviaria (traza del ferrocarril, rutas principales y secundarias, calles y sendas) da cuenta de la evolución en las formas de vinculación del territorio con otras regiones y de la relación del pueblo con las diferentes infraestructuras, la transformación de los accesos y los cambios en la estructura urbana de los diferentes pueblos.
En el primer corte temporal estudiado (Humahuaca 1967, Tilcara 1975, Purmamarca 1964) el ferrocarril se encuentra en pleno funcionamiento. En ese mismo momento, la RN9 adquiere gran importancia gracias a su pavimentación. Existen también otras conexiones (rutas provinciales y caminos consolidados), en sentido Norte-Sur (paralelos a la RN9 y al FFCC), que vinculan pueblos y parajes cercanos. Paralelamente, una red de caminos transversales de menor jerarquía vinculan la $\mathrm{QH}$ con las Yungas y la Puna. La desactivación del ferrocarril en la década de 


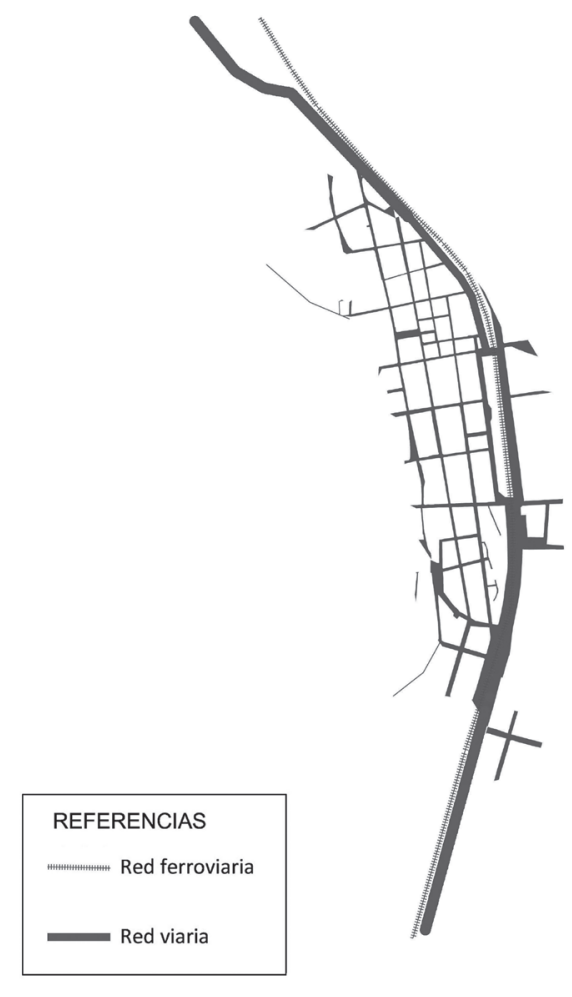

1990, la posición de la estación (refuncionalizada o desocupada) y los cambios en el trazado de la ruta y diversificación de los accesos, han sido y continúan siendo inductores y consecuencia de las transformaciones urbanas.

En Humahuaca por ejemplo, a diferencia de otros pueblos, la estación ferroviaria se encuentra en una posición central, en la parte baja del casco urbano, mientras que la ruta pasa por la parte alta del mismo. En consecuencia, se puede deducir que la accesibilidad y dinámica de este sitio, cuando estaba activo el ferrocarril, era muy diferente. Actualmente, en los edificios ferroviarios funciona una feria y la única entrada ya sea en transporte público o vehículo particular, se produce desde la RN9.

El pueblo de Tilcara, como ya se ha mencionado, está emplazado en la margen izquierda del Río Grande. La RN9y la estación del ferrocarril se encuentran en la otra margen, comunicados por un puente que existe desde la década de 1970. La estación, durante su funcionamiento, constituía un lugar de intercambio y comercio dinamizador para el pueblo. Hoy los edificios ferroviarios están abandonados y son parcialmente utilizados para otras actividades (taller de artesanías y experimentación con energía solar).

Si bien el cierre del ferrocarril implicó en Purmamarca, un cambio para sus pobladores (que

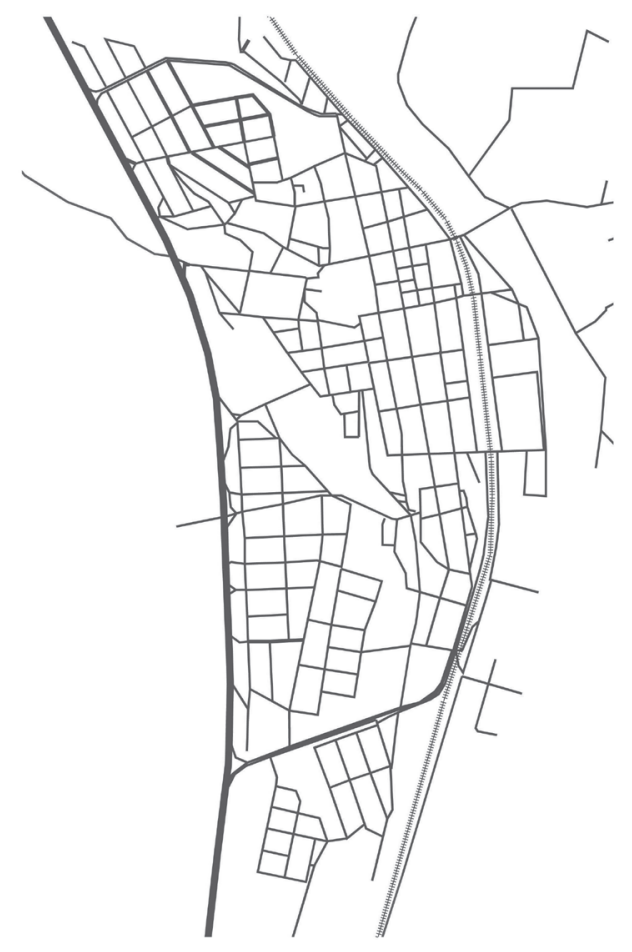

Figura 12.

Red viaria y ferroviaria en Humahuaca (1967, 2004).

Fuente:

Elaboración propia.

Escala original 1:10.000.
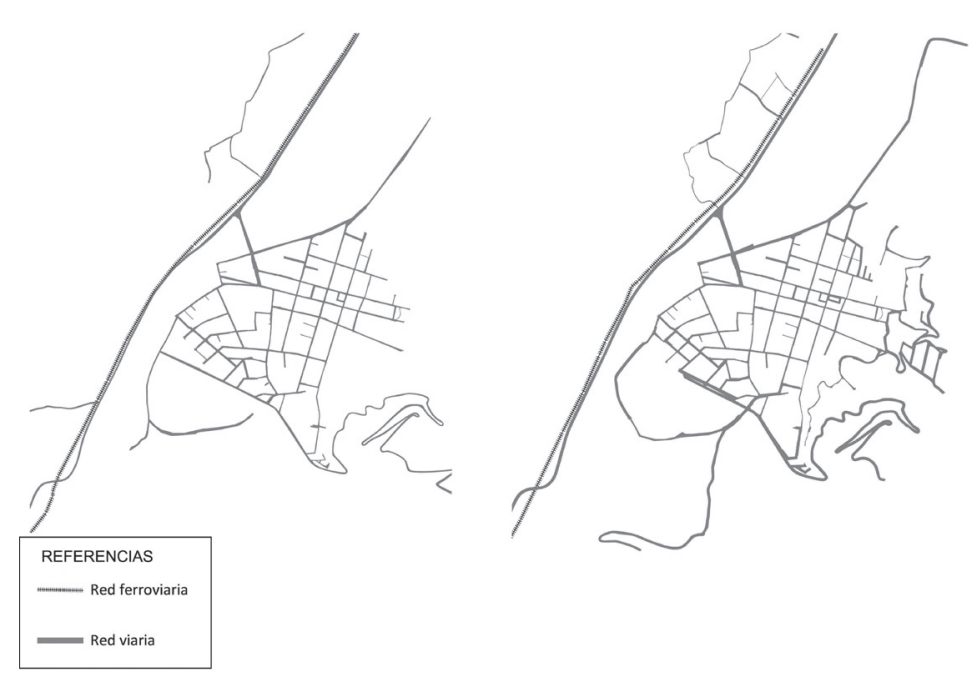

lo utilizaban como medio de transporte personal y de mercancía), su trazado, al estar alejado del pueblo, no ha dejado huellas en la morfología urbana. En relación a la circulación vehicular, la ruta que conecta al pueblo con la RN9 era difícil de transitar hasta su pavimentación e incorporación en 1991 al sistema vial nacional (RN52) y corredor internacional ya mencionado. Los cambios en el trazado vial implicaron modificaciones en el acceso al casco urbano y actualmente es posible dirigirse hacia el oeste, sin necesidad de atravesar el área urbanizada (Tommei y Benedetti, 2011).
Fig. 13.

Red viaria y ferroviaria en Tilcara $(1975,2004)$. Fuente:

Elaboración propia. Escala original 1:10.000. 

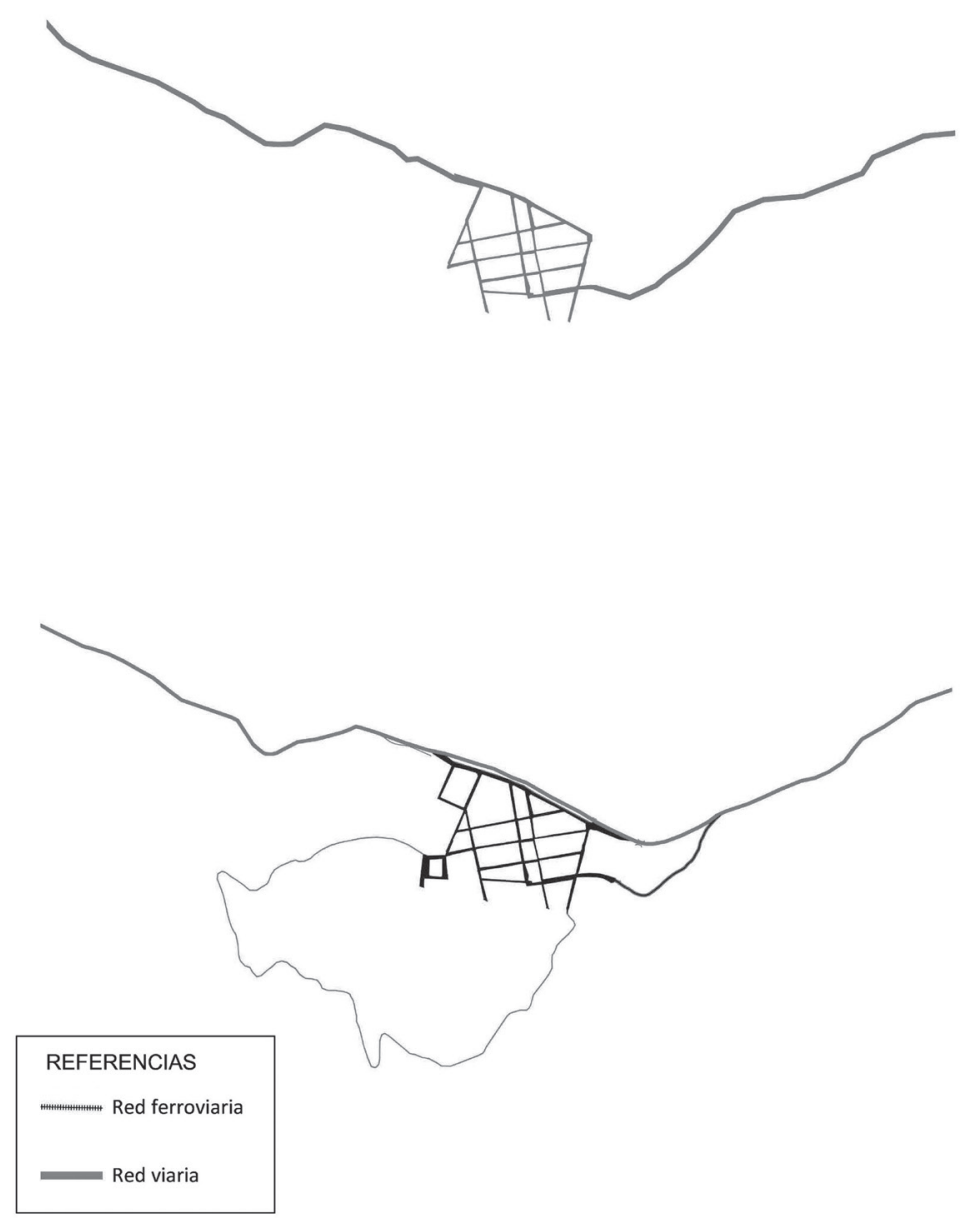

Figura 14. Red viaria y ferroviaria en Purmamarca (1964, 2004).

Fuente:

Elaboración propia. Escala original 1:10.000.

10. Más de la mitad del total de las viviendas sociales construidas en la QH se encuentran en Humahuaca (Potocko, 2011a). Según datos facilitados por el Instituto de Vivienda y Urbanismo de Jujuy en el año 2010, por lo menos diez manzanas de este pueblo fueron construidas por el gobierno en las últimas décadas.

11. Luego se construyó un conjunto de 50 viviendas del Programa Federal Construcción de Viviendas, 24 viviendas de Caritas, 72 viviendas del Programa Federal de Emergencia Habitacional con cooperativas municipales y 292 del mismo programa a través de Tupac Amaru (Potocko, 2011a). hoteleras. En la escala 1:10.000 se observa la expansión de la mancha urbana y gracias al análisis que se realizó a escala 1:25.000, es posible ver el surgimiento de nuevos lugares de asentamiento alejados de los cascos tradicionales pero en dependencia funcional con los mismos.

En este sentido, Humahuaca resulta representativa de un crecimiento por agregación de nuevas manzanas que en tan solo cuatro décadas, casi duplicaron la superficie urbanizada continua. Mientras que el área fundacional, ubicada entre la barranca del cerro Santa Bárbara y el Río Grande, tenía en 1960 aproximadamente 60 manzanas consolidadas, en la década de 2000 se reconocen más de 90 . Esta expansión se dio principalmente hacia el sector alto, superando las barreras topográficas existentes y muy incipientemente, hacia la margen izquierda del Río Grande. El crecimiento se puede relacionar tanto con la construcción de vivienda social ${ }^{10}$, como con el incremento de la actividad turística que durante la última década, implicó el paso de siete a 38 alojamientos hoteleros registrados por la Secretaría de Turismo. Asimismo, no es de soslayar el aumento demográfico experimentado por la llegada de antiguos trabajadores de la mina El Aguilar y sus familias que migraron al núcleo urbano de Humahuaca durante la década de 1990.

El análisis del pueblo a escala 1:25.000 denota una importante incidencia de la hidrografía en relación a la ocupación del suelo. Por un lado destaca la expansión rururbana del pueblo en el fondo del valle, sobre terrenos antiguamente agrícolas. Por otro, se visualiza el surgimiento del barrio 2 de Abril a partir de un loteo fiscal realizado en seis manzanas al norte del pueblo, por fuera de la trama urbana, entorno de un predio de EJESA (empresa de energía eléctrica) ${ }^{11}$.

En el caso del pueblo de Tilcara, mientras que en 1970 este comprendía aproximadamente 40 manzanas dentro de un área urbana que medía cerca de $0,9 \mathrm{~km}^{2}$, tres décadas después se registran 30 manzanas nuevas, llegando a una superficie de aproximadamente $1,3 \mathrm{~km}^{2}$. El crecimiento urbano hacia el este, sobre la ladera del Cerro Negro se ve en plena ocupación y más arriba surgen una serie de construcciones dispersas que se van acomodando a la topografía. Hacia el suroeste, en el llamado Pueblo Nuevo se completan las manzanas que en 1970 aparecían como incipientes. Paralelamente, desde finales de la década de 1990 se inició una vertiginosa 
construcción de hoteles y otros equipamientos relacionados con el turismo, contabilizándose en el 2001, 68 alojamientos en funcionamiento.

El mayor crecimiento se distingue a escala 1:25.000 en las afuera del pueblo, donde aparecen nuevas ocupaciones dispersas, urbanas o rururbanas, que en 1975 eran netamente agrícolas. Entre los lugares más transformados, encontramos pequeños valles zigzagueantes sobre ambas márgenes del Río Grande, donde se combinan espacios de cultivos con nuevas construcciones residenciales. Asimismo, destaca por sus

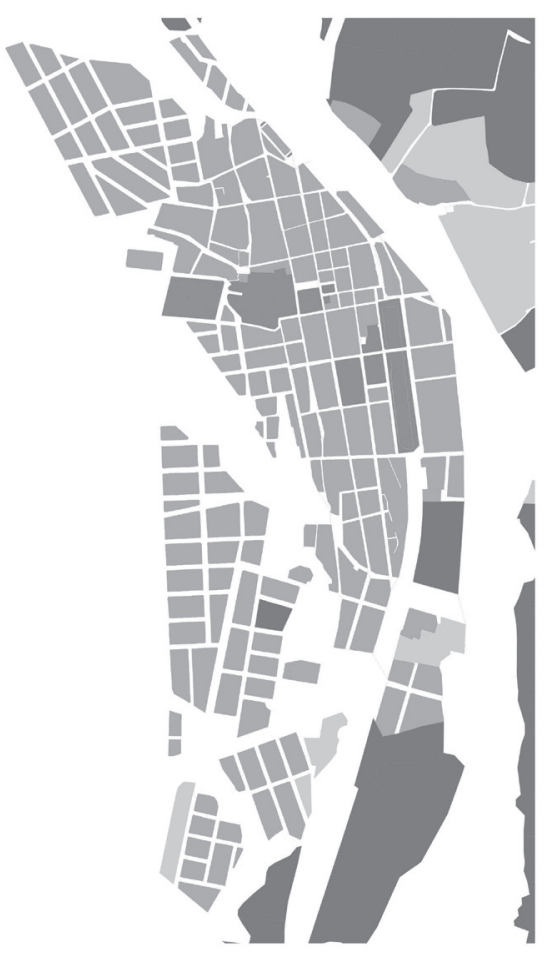

Figura 15.

Evolución de los usos del suelo en Humahuaca (1967-2004).

Fuente:

Elaboración propia. Escala original 1:10.000.

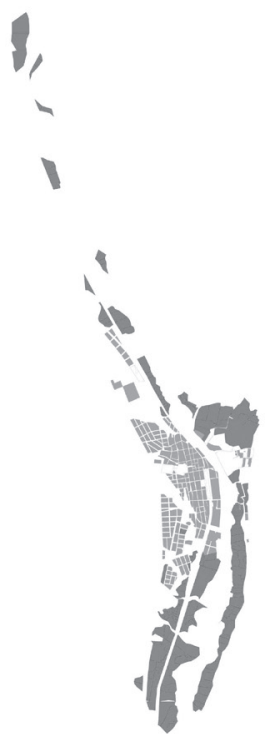

REFERENCIAS
$\quad$ Urbano
Rururbano
Rural
Sitios relevantes

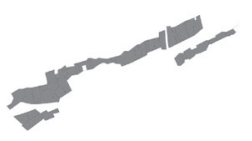

Figura 16.

Evolución de los usos del suelo en Humahuaca (1967-2004).

Fuente:

Elaboración propia. Escala original 1:25.000. 


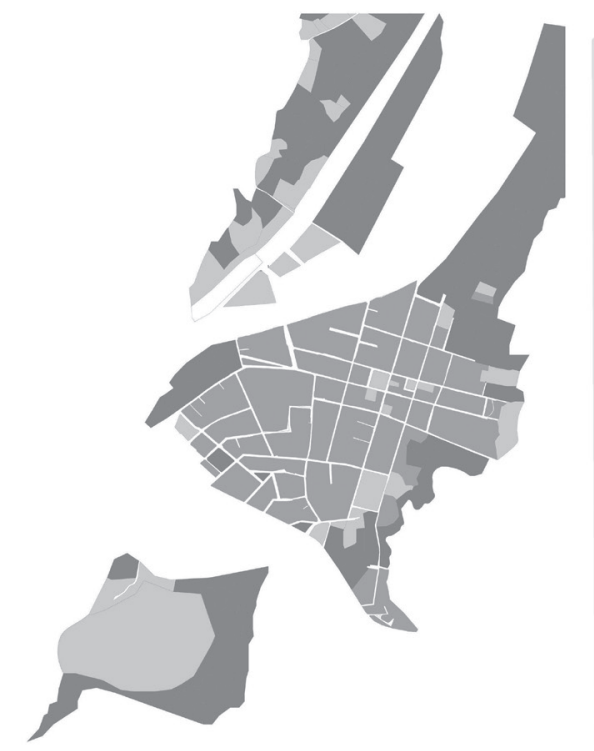

Figura 17.

Evolución de los usos del suelo en Tilcara (1975, 2010).

Fuente:

Elaboración propia. Escala original 1:10.000.

Figura 18.

Evolución de los usos del suelo en Tilcara $(1975,2010)$

Fuente:

Elaboración propia. Escala original 1:25.000.
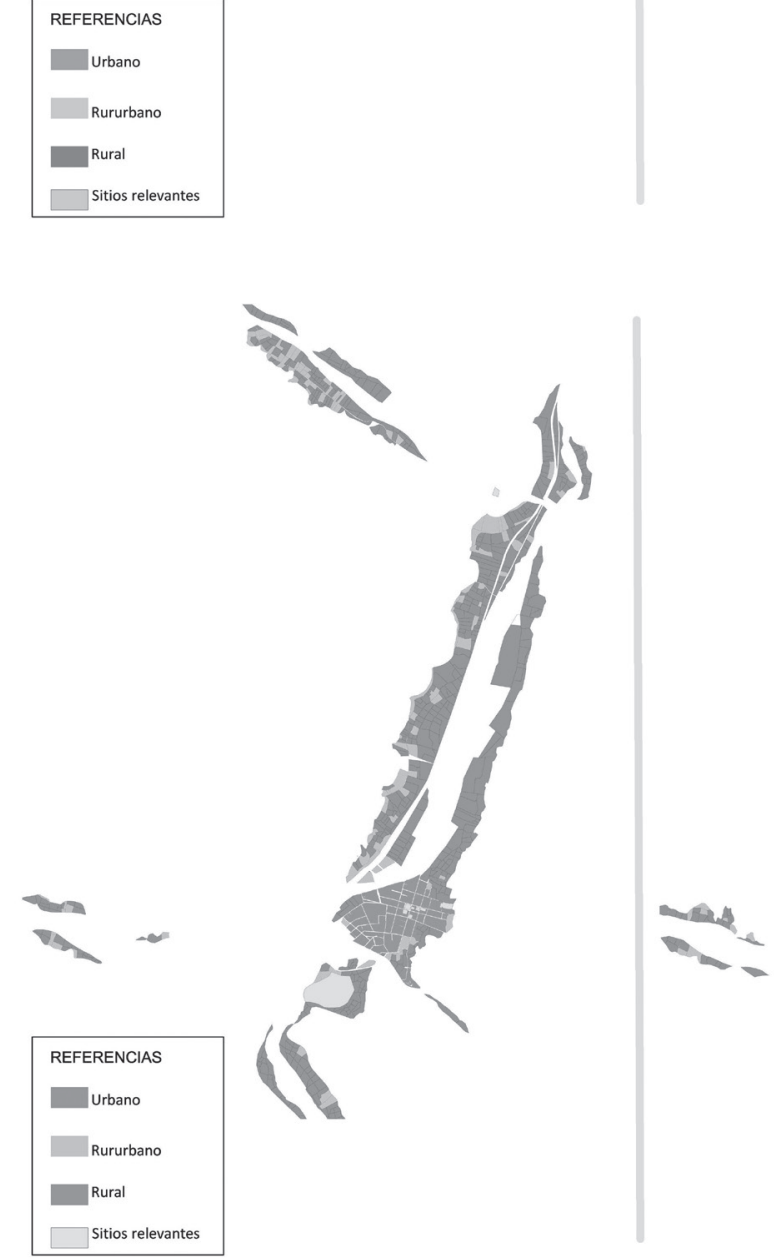

$-2$
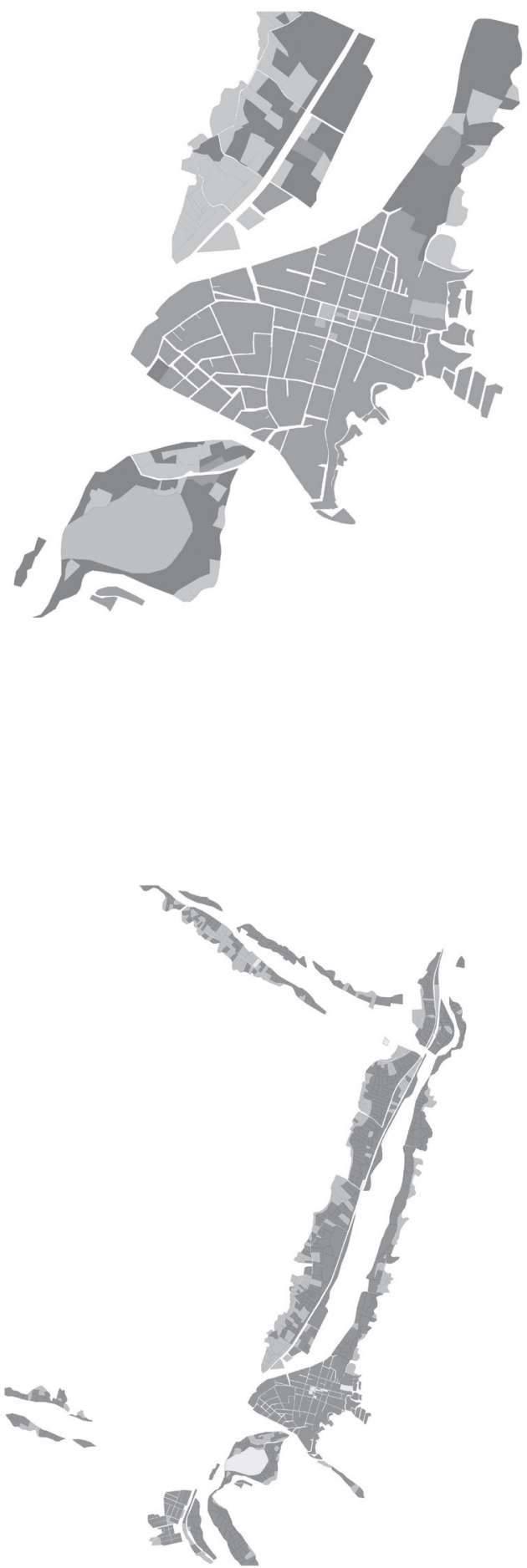

dimensiones $\left(0,26 \mathrm{~km}^{2}\right)$ y población (aproximadamente 1.300 habitantes), el paraje Sumay Pacha ubicado entre Tilcara y Maimará en un brazo de la Quebrada de Huichaira, que presenta problemas derivados de los aludes de tierra y barro durante las épocas estivales (Potocko, 2011b).

Por último, la mancha urbana de Purmamarca que hasta 1990 había permanecido sin cambios importantes, se extendió sobre el suelo rural durante las últimas dos décadas y la aglomeración quedó conformada por alrededor de 20 manzanas, junto con algunos crecimientos rururbanos 
recientes (Tommei y Benedetti, 2011). La década de 2000 es la que registró el mayor incremento en materia turística. El pueblo pasó de tener solamente algunas pocas casas de familia para el alojamiento de visitantes a contabilizar más de 60 establecimientos en funcionamiento en 2011 (Porcaro y Tommei, 2012). Al analizar el entorno del pueblo se puede observar la aparición, tras la mejora de la RN52, de nuevas formas de ocupación urbana (viviendas y establecimientos turísticos) en zonas alejadas al casco histórico, más allá de las barreras topográficas existentes. Esto ha sucedido en los terrenos adyacentes a la ruta nacional, así como en la nueva localidad de Chalala ubicada dos kilómetros hacia el oeste del casco urbano de Purmamarca, sobre la quebrada homónima que sufre de asiduos volcanes aluvionales.

\section{Reflexiones finales}

Más allá del conocimiento específico del territorio de la $\mathrm{QH}$ y de sus patrones de transformación, la combinación intencionada de algunas capas o layers de información y la generación de nuevas piezas gráficas de análisis nos permitió identificar los elementos clave de la estructura espacial, así como intuir algunos ámbitos o temas renovados de propuesta que atraviesan este territorio. En esta dirección y a modo de cierre, se plantea el debate sobre la pertinencia e inestabilidad de los límites en la planificación del territorio, la diversificación de rutas patrimoniales y el potencial aprovechamiento de los valles transversales, así como las diferentes modalidades de crecimiento en el rosario de pueblos y nuevos loteos.

\section{La inestabilidad de los límites}

En este trabajo, si bien optamos inicialmente por remitirnos al sector y la zona de amortiguación establecidos en la Declaratoria UNESCO, la delimitación más clara (aún con las mencionadas dudas en su división por sectores) es aquella que provee la lectura geográfica y el reconocimiento del accidente topográfico de la quebrada y del valle del Río Grande como una unidad espacial.

Sin embargo al mismo tiempo, los análisis y cartografías elaboradas ponen en evidencia la importancia de las relaciones transversales en este territorio, cuya progresiva pérdida puede relacionarse en primera instancia, con las transformaciones productivas y urbanas. Las conexiones
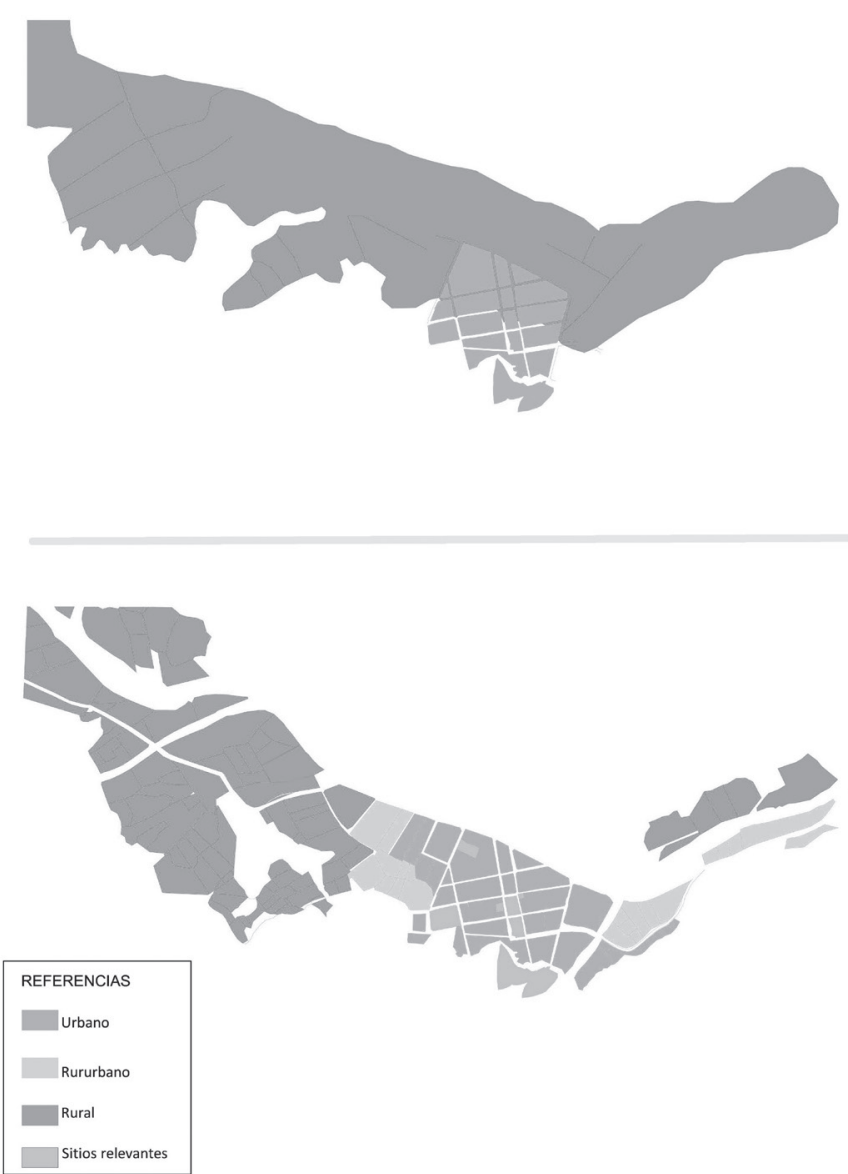

hacia las Yungas y la Puna ocurrían en gran parte, por la complementariedad de recursos de las regiones, entre las que se mantenían constantes vínculos comerciales y culturales por fuera de los circuitos de transporte moderno (Ferrocarril y RN9). El éxodo rural afectó también la forma de los recorridos y conexiones transversales. Desde una misma perspectiva, el análisis actual de este territorio varía sus dimensiones al considerar la vinculación física y articulación económica con el territorio chileno a través de la RN52 y el Paso de Jama.

Por otro lado, la QH es una construcción histórica, progresivamente individualizada dentro del espacio jujeño a lo largo de los siglos XIX y XX, cargada de resignificaciones (Benedetti, 2010). En este proceso de construcción regional, la valoración de los pueblos y del patrimonio arquitectónico y paisajístico por parte del saber académico, pero también desde las actividades y planes turísticos, registran variaciones en el tiempo incorporando (o excluyendo) dentro de sus normativas o circuitos, ciertas porciones del territorio.
Figura 19.

Evolución de los usos del suelo en Purmamarca (1967-2007).

Fuente:

Elaboración propia. Escala original 1:10.000. 


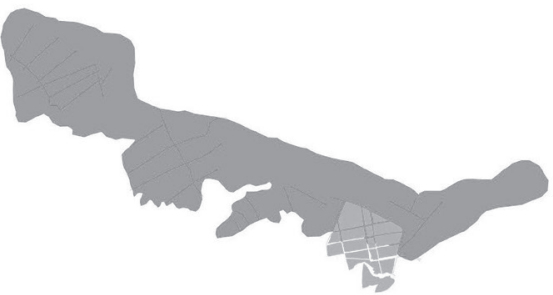

\section{Figura 20 \\ Evolución de los usos del suelo en Purmamarca \\ (1967-2007). \\ Fuente: \\ Elaboración propia.} Escala original 1:25.000.

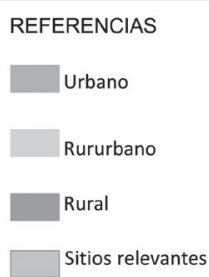

En la misma dirección, los análisis realizados sobre los pueblos y sus entornos inmediatos nos demuestran la diferente jerarquía de los mismos según su accesibilidad viaria y ferroviaria en cada momento histórico. Además de la necesidad de considerar en los respectivos códigos y zonificaciones, las áreas de influencia de los núcleos, debido al crecimiento reciente en discontinuidad con las tramas urbanas tradicionales.

Es así que la inestabilidad de los límites y su diferente valor o utilidad de acuerdo a la problemática en cuestión, reclama una cierta flexibilidad en la delimitación del territorio desde una mirada propositiva. Límites de geometría variable que a su vez, no han de ignorar la multiplicidad de divisiones administrativas (departamentos, municipios y comisiones municipales) y del planeamiento vigente (provincial, regional, local), que dan cuenta de los desfases entre los límites políticos y las incumbencias referidas a la gestión del territorio (Vecslir, Potocko y Tommei, 2011).

\section{Las rutas patrimoniales y la potencialidad} de los subsistemas transversales

La actividad turística en la $\mathrm{QH}$, como en otros casos de la zona andina, parece haber sido un 
fenómeno espontáneo y de origen exógeno. Por fuera de las promociones y planes nacionales de desarrollo turístico existentes en la región (Ballent, 2003), la forma que ha adoptado el turismo no ha dejado demasiadas opciones a las poblaciones locales para prepararse, ni en infraestructura acorde, ni para participar de su diseño o administración.

El recorrido turístico de la $\mathrm{QH}$ gestado a lo largo del siglo XX y que ha tomado su forma actual en especial desde la Declaratoria UNESCO, se organiza a lo largo de la RN9 como eje estructurante y está pensado en función de algunas localidades. Esto ha llevado al posicionamiento de Purmamarca, Tilcara y Humahuaca como destinos privilegiados cuya capacidad en muchas oportunidades (especialmente en carnaval) se ve desbordada.

En este sentido parece necesario plantear nuevas formas de recorrer la $\mathrm{QH}$, pensando este Paisaje Cultural más que como un recorrido lineal, como un sistema de servicios y recursos estructurado por itinerarios narrativos (Sabaté, 2009; Sabaté 2010). Bajo la idea de un mayor aprovechamiento del patrimonio arquitectónico, natural y cultural de este territorio, el análisis cartográfico nos demuestra la potencialidad de algunos subsistemas transversales (abras y quebradas secundarias) para la revitalización de los caminos naturales y antiguos poblados o parajes, rescatando las viejas conexiones con nuevos fines de intercambio de servicios e itinerarios turísticos.

La diversificación de rutas patrimoniales concebidas desde una perspectiva local, permitirian a su vez elegir hilos argumentales locales relativos a los diferentes períodos históricos de la $\mathrm{QH}$, sus modos de producción o actividades económicas, los recursos gastronómicos, fiestas tradicionales y folklore; patrimonio y sitios religiosos, respetando la identidad del territorio y la memoria de su gente, buscando un mayor equilibrio entre transformación turística y desarrollo local.

\section{Viejos y nuevos pueblos en construcción}

El crecimiento urbano de los diferentes pueblos encuentra en este contexto territorial fuertes condicionantes de tipo natural o geográfico (topografía, accesibilidad, provisión de servicios, riego, bajada de volcanes o aludes, etc.). Estas limitaciones, sumadas al incremento de los precios en los lotes urbanos, han llevado al planteamiento de nuevas alternativas de expansión en las afueras de los núcleos tradicionales en discontinuidad con la trama existente, superando así antiguas barreras físicas (cerros, río, ruta).

Como parte de procesos generales de la región, se experimentó un significativo incremento poblacional en las áreas urbanas analizadas (Humahuaca, Tilcara y Purmamarca y en alguna medida Maimará). Los motivos de este proceso incluyen, además del boom turístico, las migraciones regionales desde áreas rurales, minas o fábricas que bajaron su actividad significativamente y las migraciones desde varios puntos del país para trabajar en hotelería o actividades afines. Esta situación generó un desplazamiento de la población local, especialmente de aquella que alquilaba en tiempos previos a la Declaratoria y una creciente demanda de acceso a la vivienda. Como respuesta aparecen los planes de vivienda y los nuevos asentamientos o tomas de tierras, concentrados en determinados puntos de la $\mathrm{QH}$. Los lotes urbanos se densifican y las parcelas agrícolas (de actividad part time, destinada al autoconsumo) se convierten progresivamente en suelo rururbano, acarreando problemas antes desconocidos, como el tratamiento de basura, la saturación de los desagües cloacales, o la falta temporal de agua.

Desde esta perspectiva resulta clave en la gestión de este territorio, relacionar o pensar simultáneamente los potenciales itinerarios patrimoniales y la reactivación de algunos subsistemas transversales, junto con la regulación del crecimiento en las áreas de influencia de los núcleos urbanos originales, de manera tal que no afecten los modos de vida, los recursos paisajísticos y las actividades tradicionales. En sintesis se requiere de un planeamiento regional que afronte la principal contradicción de este territorio: sostener el desarrollo del turismo sin que este sea motor de destrucción del paisaje y del modo de vida que le ha valido a la $\mathrm{QH}$ el ser declarada como Patrimonio de la Humanidad.

\section{Referencias}

Arzeno, M. y Castro, H. (1998). Caracterización socio-ambiental de la Quebrada de Humahuaca (Jujuy, Argentina). Documento de Trabajo, Proyecto Ambiente y Sociedad en los Andes: estrategias y políticas, Buenos Aires: Instituto de Geografía (FFyl-UBA). 
Ballatore, 1. (2005). Jama. La causa que movió montañas. Buenos Aires: Ed. PGA.

Ballent, A. (2003). Monumentos, turismo e historia: imágenes del noroeste en la arquitectura promovida por el Estado, 1935-1945. Seminario Estado y políticas públicas, Universidad Nacional de Quilmes.

Benedetti, A. (2003). Les effets de l'incorporation. Transformations territoriales et réorganisation de l'habitat à Jujuy, République d'Argentine, durant leXXe siècle. Histoire des Alpes - Storia delle Alpi 8, (pp. 99-121). Lugano: Istituto di Storia delle Alpi, Università della Svizzera italiana.Benedetti, A. (2010) Quebrada de Humahuaca: ¿hoya, unidad fisiográfica, región geográfica, ambiente o lugar? Estudio bibliográfico sobre la toponimia y el pensamiento geográfico regional argentino (siglos XIX y XX). Registros, 7, 111-138.

Clementi, A., Dematteis, G. y Palermo, P. C. (1996). Le forme del territorio italiano. Roma-Bari: Laterza.

Corboz, A. (1983). El territorio como palimpsesto. En A.M. Ramos (Ed.) Lo urbano en 20 autores contemporáneos (pp.25-34). Barcelona: Ediciones UPC.

Gonzalez M, Baumann, V. y Jackson, L. (2009). Estudio de los flujos ocurridos en el 2007 en Chalala y Coquena, Purmamarca, Provincia de Jujuy. Revista de la Asociación Geológica Argentina 65 (4), 791-804.

Janoschka, M. (2003). El turismo en la Quebrada. En Reboratti, C. (Coord.) La Quebrada. Geografía, historia y ecología (pp. 211-224). Buenos Aires: La Colmena.

Mancini, C. (2011). La construcción de la Quebrada de Humahuaca como paisaje cultural. En Seminario de Crítica $N^{\circ}$ 169: Las transformaciones del territorio. Mapas, patrimonio y lugares de la Quebrada de Humahuaca (pp. 17-23). Buenos Aires: Instituto de Arte Americano, Universidad de Buenos Aires.

Mancini, C. y Tommei, C. (2012). Transformaciones de la Quebrada de Humahuaca (Jujuy) en el siglo XX. Entre destino turístico y bien patrimonial. Registros, 9, 97-116.

Porcaro, T. y Tommei, C. (2012, 13-14 de septiembre). Alojarse en Purmamarca, Jujuy. Acciones privadas en la construcción de un destino turístico. Jornadas Internacionales Patrimonio y Cultura Urbana. Rosario, Argentina. Publicado en Actas (CD) del evento.
Potocko, A. (2011a, 29 de noviembre a 2 de diciembre). Configuración de la Quebrada de Humahuaca a partir de la ejecución de políticas de vivienda. $X$ Congreso Argentino de Antropología Social. Buenos Aires.

Potocko, A. (2011b). Sumay Pacha y los programas de vivienda federales. En Seminario de Crítica $N^{\circ}$ 169: Las transformaciones del territorio. Mapas, patrimonio y lugares de la Quebrada de Humahuaca (pp. 27-32). Instituto de Arte Americano, Universidad de Buenos Aires.

Reboratti, C., García, J. C., Albeck, M., Castro, H. y Arzeno, M. (2003). Una visión general de la Quebrada. En C. Reboratti (Coord.). La Quebrada: geografía, historia y ecología de la Quebrada de Humahuaca (pp. 17-46). Buenos Aires: La Colmena.

Rotondaro, R. (2001) Arquitectura y tecnología en la Quebrada de Humahuaca. Transformación de los patrones tradicionales e impacto cultural. Presentación para la inclusión de la Quebrada de Humahuaca en la Lista Indicativa de Bienes propuesta por la República Argentina al Comité del Patrimonio Mundial. Sabaté, J. (2009) Paisatges culturals: una pregunta, dues definicions, tres escenaris i una alternativa. En Paisatges en transformació. Intervenció i gestió paisatgístiques (pp. 6777). Barcelona: Colecció Estudis - Diputación de Barcelona.

Sabaté, J. (2010). Algunas pautas metodológicas en los proyectos en paisajes culturales. En L. Moya, (Coord.) La práctica del urbanismo (pp. 101-122). Madrid: Editorial Sintesis.

Secchi, B. (coord.) (1993-94). Quaderno della ricerca sulle trasformazioni dell'habitat urbano in Europa, 1 y 2, Venezia: IUAV.

Solà-Morales, M. (1981). La identidad del territorio. Quaderns d'Arquitectura i Urbanisme, Extra Comarcas, 1, 3.

Tommei, C. y Benedetti, A. (2011, 7-9 de septiembre). Un pueblo boutique. La construcción de Purmamarca como lugar de atractivo turístico. IV Jornadas Hum.H.A. Imaginando el espacio: problemas, prácticas y representaciones, Bahía Blanca, Argentina.

Troncoso, C. (2008). Turismo, desarrollo y participación local. La experiencia de quebrada de Humahuaca (Jujuy, Argentina). Aportes y Transferencias, 12 (2), 110-130. 
Troncoso, C. y Almirón, A. (2005). Turismo y patrimonio. Hacia una relectura de sus relaciones. Aportes y transferencias, 1 (009), 56-74.

UNESCO (2002). Quebrada de Humahuaca Un itinerario cultural de 10.000 años. Propuesta para la Inscripción a la Lista de Patrimonio Mundial de la UNESCO. Provincia de Jujuy, República Argentina.
Vecslir, L., Potocko A. y Tommei, C. (2011). Graficas interpretativas. En Seminario de Crítica $N^{\circ}$ 169: Las transformaciones del territorio. Mapas, patrimonio y lugares de la Quebrada de Humahuaca (pp. 11-16). Instituto de Arte Americano, Facultad de Arquitectura, Diseño y Urbanismo, Universidad de Buenos Aires.

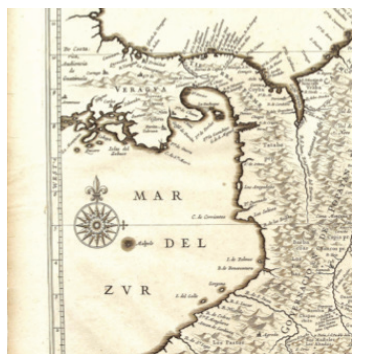

